\title{
Matrix metalloproteinase-9 (MMP9) is involved in the TNF-a-induced fusion of human M13SV1-Cre breast epithelial cells and human MDA-MB-435-pFDR1 cancer cells
}

\author{
Julian Weiler ${ }^{1}$, Marieke Mohr², Kurt S. Zänker ${ }^{1}$ and Thomas Dittmar ${ }^{1 *}$ (D)
}

\begin{abstract}
Background: In addition to physiological events such as fertilisation, placentation, osteoclastogenesis, or tissue regeneration/wound healing, cell fusion is involved in pathophysiological conditions such as cancer. Cell fusion, which applies to both the proteins and conditions that induce the merging of two or more cells, is not a fully understood process. Inflammation/pro-inflammatory cytokines might be a positive trigger for cell fusion. Using a Cre-LoxP-based cell fusion assay we demonstrated that the fusion between human M13SV1-Cre breast epithelial cells and human MDA-MB-435-pFDR1 cancer cells was induced by the pro-inflammatory cytokine tumour necrosis factor-a (TNF-a).

Methods: The gene expression profile of the cells in the presence of TNF-a and under normoxic and hypoxic conditions was analysed by cDNA microarray analysis. CDNA microarray data were verified by qPCR, PCR, Western blot and zymography. Quantification of cell fusion events was determined by flow cytometry. Proteins of interest were either blocked or knocked-down using a specific inhibitor, siRNA or a blocking antibody.

Results: The data showed an up-regulation of various genes, including claudin-1 (CLDN1), ICAM1, CCL2 and MMP9 in M13SV1-Cre and/or MDA-MB-435-pFDR1 cells. Inhibition of these proteins using a blocking ICAM1 antibody, CLDN1 siRNA or an MMP9 inhibitor showed that only the blockage of MMP9 was correlated with a decreased fusion rate of the cells. Likewise, the tetracycline-based antibiotic minocycline, which exhibits anti-inflammatory properties, was also effective in both inhibiting the TNF-a-induced MMP9 expression in M13SV1-Cre cells and blocking the TNF-a-induced fusion frequency of human M13SV1-Cre breast epithelial cells and human MDA-MB435-pFDR1 cancer cells.

Conclusions: The matrix metalloproteinase-9 (MMP9) is most likely involved in the TNF-a-mediated fusion of human M13SV1-Cre breast epithelial cells and human MDA-MB-435-pFDR1 cancer cells. Likewise, our data indicate that the tetracycline-based antibiotic minocycline might exhibit anti-fusogenic properties because it inhibits a cell fusion-related mechanism.
\end{abstract}

Keywords: Cell fusion, TNF-a, Minocycline, MMP9, Breast cancer

\footnotetext{
* Correspondence: thomas.dittmar@uni-wh.de

${ }^{1}$ Institute of Immunology, Centre of Biomedical Education and Research

(ZBAF), Witten/Herdecke University, Stockumer Str. 10, 58448 Witten,

Germany

Full list of author information is available at the end of the article
}

(c) The Author(s). 2018 Open Access This article is distributed under the terms of the Creative Commons Attribution 4.0 International License (http://creativecommons.org/licenses/by/4.0/), which permits unrestricted use, distribution, and reproduction in any medium, provided you give appropriate credit to the original author(s) and the source, provide a link to the Creative Commons license, and indicate if changes were made. The Creative Commons Public Domain Dedication waiver (http://creativecommons.org/publicdomain/zero/1.0/) applies to the data made available in this article, unless otherwise stated. 


\section{Background}

Even though cell fusion has a pivotal role in several physiological and pathophysiological conditions such as fertilisation, placentation, muscle development, osteoclastogenesis, wound healing, tissue regeneration, infection with enveloped viruses, and cancer (for review see: [1-4]), the conditions that favour and the detailed mechanisms of how the plasma membranes of two or more cells merge are not fully understood.

During evolution different cell fusion strategies developed using different proteins and protein-protein interactions. Some cell fusion-mediating proteins, such as EFF-1 in $C$. elegans and members of the syncytin family (syncytin-1 and syncytin-2 in humans or syncytin- $A$ and syncytin $-B$ in mice) are of viral and retroviral origin (for review see: $[1,5,6])$. Because of the high homology of these proteins to viral fusion proteins, the cell fusion mechanisms might conceivably be similar. Syncytin-1 and syncytin-2 are expressed in trophoblasts and mediate their fusion to multi-nucleated syncytiotrophoblasts [5]. Trophoblast fusion depends on cyclic AMP (cAMP)/ PKA- and PKC-dependent mechanisms [7]. In contrast, the fusion of myoblasts to multinucleated myofibres chiefly depends on the reorganisation of the actin cytoskeleton and the interplay of several actin regulatory proteins (for review see: [8]). In order to fuse with osteoclasts, the macrophages first have to adopt a fusioncompetent status, which is induced through several cytokines, including IL-4, IL-13, M-CSF and RANKL, and surface molecules such as TREM-2 and DAP12 (for review see: [9]). Fusion-competent macrophages are characterised by the expression of several markers, including E-cadherin, DC-STAMP/OC-STAMP, CD200, SIRP $\alpha$, CD9 and CD81, CCL2, and MMP9 (for review see: [9]). The fusion of mesenchymal stem cells with MDA-MB231 breast cancer cells depends on S100A4 [10].

The induction of a fusion-competent status indicates that the cells per se are not fusogenic, but rather, have to acquire the ability to fuse, which has been termed priming [4]. In addition to priming, four additional steps have been proposed for the entire cell fusion process, namely, chemotaxis, adhesion, fusion and post-fusion (an excellent and detailed overview is given in [4]). Fusion-competent cells have to migrate towards their cellular fusion partners by chemotaxis and close cell-cell contact is a prerequisite for the subsequent fusion step. As important as the induction of a fusion-competent status is, fused cells must finally acquire a fusionincompetent status to prevent further cell fusion events.

Even though factors have been identified that induce a fusion-competent status in macrophages, the regulation of the entire process but particularly basal cell fusion events that occur between different body cell types, is not understood. In addition to macrophages [11], basal cell fusion events were also observed for bone marrowderived stem cells (BMDCs) [12], intestinal cells [13], and haematopoietic cells [14]. It is unclear how these spontaneous cell fusion events are regulated. However, the data from several studies indicated an increased cell fusion frequency under injurious/inflammatory conditions. For instance, the fusion frequency of bone marrow-derived stem cells (BMDCs) with epithelial intestinal cells and Purkinje neurons is markedly increased in response to chronic inflammation $[13,15]$. Likewise, an increased fusion frequency for different cell types, including macrophages and tumour cells, was observed in the presence of the pro-inflammatory cytokine TNF- $\alpha$ [16-19]. In this context, it is worth speculating whether the chronically inflamed tumour microenvironment $[20,21]$ would also provide a fusion-friendly milieu. It is wellknown that tumour cells could fuse with tumour cells and normal cells, like macrophages and stem cells, thereby giving rise to hybrid cells that could exhibit novel properties, such as an enhanced metastatic capacity and an increased drug resistance (for review see: [22-24]).

To clarify whether the fusion of tumour cells and normal cells is triggered by cytokines, chemokines and/or growth factors, we developed a Cre-LoxP-based cell fusion assay [18]. Human breast cancer cells were stably transfected with a fluorescence double reporter (FDR) plasmid containing a loxP flanked HcRed/DsRed cassette followed by an EGFP cassette and were co-cultured with Cre recombinase-expressing human breast epithelial cells [18]. The Cre-mediated recombination in fused cells led to a switch from red fluorescence to green fluorescence that could be easily quantified by flow cytometry [18]. Using this assay we were able to show that the fusion of human breast cancer cells and human breast epithelial cells was positively triggered by TNF- $\alpha$ in a dose-dependent manner [18].

Here, we investigated the impact of TNF- $\alpha$-induced protein expression on cell fusion. MMP9 was markedly up-regulated in TNF- $\alpha$ treated cells and the inhibition of MMP9 activity was correlated with a significantly impaired TNF- $\alpha$-induced fusion rate. Similar results were achieved using the tetracycline-based antibiotic minocycline, which also has anti-inflammatory properties (for review see: [25]).

\section{Methods}

\section{Cell culture}

M13SV1-Cre-Puro human breast epithelial cells and MDA-MB-435-pFDR1 human cancer cells were generated as previously described [18]. The pFDR1 vector [26] was kindly provided by Frank Edenhofer (University of Würzburg, Würzburg, Germany). M13SV1-mCherry-Cre human breast epithelial cells were derived from M13SV1 human breast epithelial cells [27] by stable transduction 
with the pcDNA-mCherry-P2A-Cre vector. This vector was derived by excising the mCherry-P2A-Cre sequence of pLM-CMV-R-Cre (a gift from Michel Sadelain (Addgene plasmid \#27546)) with NheI and SalI (both restriction enzymes were purchased from ThermoFisher Scientific GmbH, Schwerte, Germany) and cloning it into the pcDNA3.1 vector digested with NheI and XhoI (vector and restrictions enzymes were obtained from ThermoFisher Scientific GmbH, Schwerte, Germany). XhoI and Sall have identical cohesive ends. M13SV1-Cre-Puro and M13SV1-mCherry-Cre human breast epithelial cells (M13SV1-Cre cells) were cultivated in MSU-1 basal media (Biochrom GmbH, Berlin, Germany) supplemented with $10 \%$ foetal calf serum (FCS; Biochrom $\mathrm{GmbH}$, Berlin, Germany), $1 \%$ penicillin/streptomycin $(100 \mathrm{U} / \mathrm{ml}$ penicillin, $0.1 \mathrm{mg} / \mathrm{ml}$ streptomycin; Sigma-Aldrich, Taufkirchen, Germany), $10 \mu \mathrm{g} / \mathrm{ml}$ human recombinant EGF, $5 \mu \mathrm{g} / \mathrm{ml}$ human recombinant insulin, $0.5 \mu \mathrm{g} / \mathrm{ml}$ hydrocortisone, $4 \mu \mathrm{g} / \mathrm{ml}$ human transferrin, $10 \mathrm{nM} \beta$-oestrogen (all chemicals were purchased from Sigma-Aldrich, Taufkirchen, Germany) and $1 \mu \mathrm{g} / \mathrm{ml}$ puromycin (InvivoGen, Toulouse, France). MDA-MB-435-pFDR1 cells were cultivated in DMEM media (Sigma-Aldrich, Taufkirchen, Germany) supplemented with 10\% FCS (Biochrom GmbH, Berlin, Germany), $1 \%$ penicillin/ streptomycin $(100 \mathrm{U} / \mathrm{ml}$ penicillin, $0.1 \mathrm{mg} / \mathrm{ml}$ streptomycin; Sigma-Aldrich, Taufkirchen, Germany), and $2 \mu \mathrm{g} / \mathrm{ml}$ puromycin (InvivoGen, Toulouse, France). All cells were maintained in a humidified atmosphere at $37^{\circ} \mathrm{C}$ and $5 \% \mathrm{CO}_{2}$.

\section{Cell fusion assay}

Quantification of fusion events between M13SV1-Cre cells and MDA-MB-435-pFDR1 cells was performed as previously described [18]. Briefly, M13SV1-Cre human breast epithelial cells and MDA-MB-435-pFDR1 human breast cancer cells were co-cultured in a ratio of 1:3 per well of a 96-well plate for $72 \mathrm{~h}$ in a humidified atmosphere at $37{ }^{\circ} \mathrm{C}$ and $5 \% \mathrm{CO}_{2}$. Depending on the experiment $100 \mathrm{ng} / \mathrm{ml}$ TNF- $\alpha$ (Bio-Techne $\mathrm{GmbH}$, Wiesbaden-Nordenstadt, Germany), up to $10 \mu \mathrm{g} / \mathrm{ml}$ minocycline (Sigma-Aldrich, Taufkirchen, Germany), up to $10 \mu \mathrm{M}$ SB-3CT (Sigma Aldrich, Taufkirchen, Germany), $10 \mu \mathrm{g} / \mathrm{ml}$ anti-ICAM1/CD54 (mouse monoclonal, clone 11C81; Bio-Techne $\mathrm{GmbH}$, WiesbadenNordenstadt, Germany) and appropriate combinations of inhibitors and TNF- $\alpha$ were added to the cell culture media. Hypoxia was induced by culturing the cells in stepwise oxygen-deprivation conditions ( $24 \mathrm{~h}$ with $10 \%$ $\mathrm{O}_{2}, 24$ h with $5 \% \mathrm{O}_{2}, 24$ h with $1 \% \mathrm{O}_{2}$ ) in hypoxia chambers (Billups-Rothenberg, Del Mar, CA, USA) with a constant flow of $5 \% \mathrm{CO}_{2}$ and the remainder of nitrogen, as previously described [18]. All co-cultured cells were harvested, washed once with PBS and the amount of EGFP-expressing cells was quantified by flow cytometry
(FACSCalibur; Becton Dickenson, Heidelberg, Germany). Freshly harvested M13SV1-Cre cells and MDA-MB-435-pFDR1 cells mixed in a ratio of 1:3 served as a negative control to adjust the flow cytometer. The relative fold change was calculated in relation to untreated co-cultured cells, which was set to 1. Each condition was assayed in triplicate.

\section{Total RNA preparation}

Total RNA from all the cell lines/cells used in this study was isolated using the NucleoSpin ${ }^{\bullet}$ RNA Kit (Macherey Nagel, Düren, Germany) according to the manufacturer's instructions. For PCR and qPCR, RNA concentration and purity was determined by UV spectrophotometric analysis. For subsequent cDNA microarray studies, the RNA integrity number (RIN) was determined using an Agilent 2100 Bioanalyzer (Agilent Technologies, Waldbronn, Germany). The samples were diluted to a final concentration of $500 \mathrm{ng} / \mu \mathrm{l}$ and applied to an RNA chip according to the manufacturer's instructions. RNA samples with a RIN of 8 to 10 were used for microarray analysis.

\section{Single-colour microarray analysis}

To investigate differential gene expression after the TNF- $\alpha$ stimulation of MDA-MB-435-pFDR1 and M13SV1-CrePuro cells under normoxia and hypoxia, a single colour microarray analysis (Agilent Human $4 \times 44 \mathrm{~K}$ v2 Microarray (Agilent Technologies, Waldbronn, Germany)) was performed. The total RNA of the cells (three independent experiments were pooled) matching the RIN criteria of 8 to 10 were sent on dry ice to Source BioSciences (Nottingham, UK), which performed synthesis and Cy3 labelling of the cDNA and hybridisation of the microarrays. Microarray gene expression data were analysed using GeneSpring GX v14.8 software (Agilent Technologies, Waldbronn, Germany). Expression data were normalized based on quantiles with a threshold of 1 and no baseline transformation was performed. For further analysis, data were filtered by flags (not detected flags and compromised spots were removed) and fold changes (2-fold up and down). All microarray data were deposited in the ArrayExpress database at EMBL-EBI (https://www.ebi.ac.uk/arrayexpress) under accession number E-MTAB-6084.

\section{RT-PCR and $\mathrm{qPCR}$}

Synthesis of cDNA from mRNA by reverse transcription was performed using the RevertAid First Strand cDNA Synthesis Kit (ThermoFisher Scientific GmbH, Schwerte, Germany) as referred to in the instruction manual. Conventional PCR (total reaction volume of $25 \mu \mathrm{l}$ ) was performed with ready to use $5 \times$ Master Mix containing Bio\&Sell Taq-Polymerase, dNTPs and $\mathrm{MgCl}_{2}$ (Bio\&Sell $\mathrm{GmbH}$ Nuremberg, Germany) and $10 \mu \mathrm{M}$ primers 
(ThermoFisher Scientific GmbH, Schwerte, Germany). Cycling conditions comprised of an initial denaturation for $5 \mathrm{~min}$ at $94{ }^{\circ} \mathrm{C}$ and 30 cycles of $30 \mathrm{~s}$ at $94{ }^{\circ} \mathrm{C}, 30 \mathrm{~s}$ at the appropriate annealing temperature and $30 \mathrm{~s}$ at $72{ }^{\circ} \mathrm{C}$ followed by final elongation for $7 \mathrm{~min}$ at $72{ }^{\circ} \mathrm{C}$. Primer pairs used in this study are summarised in Table 1. PCR products were separated on a $1.5 \%$ agarose gel and the bands were visualized with GelRed ${ }^{\mathrm{m}}$ stain (VWR International GmbH, Darmstadt, Germany) and the GFelDoc $^{\text {Tw }}$ EZ Imager system (Bio-Rad, Munich, Germany). For qPCR (total volume of $10 \mu$ l per reaction), the SYBR Green Super Mix with ROX (Quanta Bioscience, Beverly, CA, USA) and $10 \mu \mathrm{M}$ primers (Table 1) were used according to the manufacturer's instructions. The StepOne Plus Real-Time PCR System (ThermoFisher Scientific $\mathrm{GmbH}$, Schwerte, Germany) was used for qPCR. The relative target gene expression level was determined in relation to GAPDH using the $2^{-\triangle C T}$ method.

\section{Western blot}

M13SV1-Cre cells and MDA-MB-435-pFDR1 cells were cultivated for $72 \mathrm{~h}$ at $37^{\circ} \mathrm{C}$ and $5 \% \mathrm{CO}_{2}$ under normoxic and hypoxic conditions in the presence of TNF- $\alpha$ $(100 \mathrm{ng} / \mathrm{ml})$, minocycline $(10 \mu \mathrm{g} / \mathrm{ml})$ and a combination of both. Subsequently, cells were harvested and were lysed in ice-cold RIPA buffer (50 mM Tris- $\mathrm{HCl} \mathrm{pH} \mathrm{8.0;}$ $150 \mathrm{mM} \mathrm{NaCl}, 1 \%(v / \mathrm{v}) \mathrm{NP}-40,0.5 \%(w / v)$ sodium deoxycholate, $0.1 \%(\mathrm{w} / \mathrm{v})$ sodium dodecyl sulphate) supplemented with cOmplete, Mini, EDTA-free Protease Inhibitor Cocktail (Sigma Aldrich, Taufkirchen, Germany) and Pierce Phosphatase Inhibitor Mini Tablets (ThermoFisher Scientific GmbH, Schwerte, Germany). The samples were sonicated three times $(10 \mathrm{~s}$ on and $30 \mathrm{~s}$ off) and the total protein concentration was determined using the Pierce ${ }^{\mathrm{Tu}}$ BCA Protein Assay Kit (ThermoFisher Scientific GmbH, Schwerte, Germany) according to the manufacturer's instructions. For Western blots, $40 \mu \mathrm{g}$ of total protein lysate was mixed with $3 \times$ Laemmli Sample Buffer and was incubated for $6 \mathrm{~min}$ at $95{ }^{\circ} \mathrm{C}$. The samples were separated by $10 \%$ or $15 \%$ sodium dodecyl sulphate-polyacrylamide gel electrophoresis (SDS-PAGE) and transferred to an Immobilon polyvinyl difluoride (PVDF) nitrocellulose membrane (Merck Millipore, Darmstadt, Germany) under semi-dry conditions. The membranes were blocked in 5\% $(w / v)$ non-fat milk powder in PBS-T (phosphate-buffered saline) with $0.1 \%(v / v)$ Tween $20(\mathrm{PBS}-\mathrm{T})$ for $1 \mathrm{~h}$ at room temperature. The following antibodies were used for Western blot analysis: anti-MMP9 (rabbit monoclonal; Abcam, Cambridge, UK), anti-CCL2 (MCP-1; rabbit

Table 1 Summary of PCR/qPCR primer pairs

\begin{tabular}{|c|c|c|c|c|}
\hline Name & $P C R / q P C R$ & Mean product size & Primer & Sequence ( $5^{\prime}$ to $3^{\prime}$ ) \\
\hline \multirow[t]{2}{*}{ MMP9 } & $\mathrm{qPCR}$ & $106 \mathrm{bp}$ & forward & TTCCAAACCTITGAGGGCGA \\
\hline & & & reverse & CAAAGGCGTCGTCAATCACC \\
\hline \multirow[t]{2}{*}{ ICAM1 } & qPCR & $149 \mathrm{bp}$ & forward & GGTAGCAGCCGCAGTCATAA \\
\hline & & & reverse & GATAGGTTCAGGGAGGCGTG \\
\hline \multirow[t]{2}{*}{ CCL2 } & $P C R$ & 297bp & forward & GCTCAGCCAGATGCAATCAATG \\
\hline & & & reverse & GTGTCTGGGGAAAGCTAGGG \\
\hline \multirow[t]{2}{*}{ CLDN1 } & qPCR & $118 \mathrm{bp}$ & forward & CTGTCATTGGGGGTGCGATA \\
\hline & & & reverse & CTGGCATTGACTGGGGTCAT \\
\hline \multirow[t]{2}{*}{ ADAMTS9 } & $P C R$ & $301 \mathrm{bp}$ & forward & TTAATCTCACCGCCAATGC \\
\hline & & & reverse & GCGCTGCGCCTATAAATGAT \\
\hline \multirow[t]{2}{*}{ VEGFC } & PCR & $320 \mathrm{bp}$ & forward & CATGTACGAACCGCCAG \\
\hline & & & reverse & TTGGCTGTTTGGTCATTGGC \\
\hline \multirow[t]{2}{*}{$\mid\llcorner 4 \mid 1$} & PCR & $451 \mathrm{bp}$ & forward & TCACCAAGAGCTGGAGACACC \\
\hline & & & reverse & AACTTGGTCAGGTTGAGCCC \\
\hline \multirow[t]{2}{*}{ IL7R } & PCR & $281 \mathrm{bp}$ & forward & TAATAGCTCAGGGGAGATGGAT \\
\hline & & & reverse & CTTGCAGAAAACCTTCCACTTCA \\
\hline \multirow[t]{2}{*}{ TNFAIP3 } & PCR & $629 \mathrm{bp}$ & forward & CAACTGAAACGGGGCAAAGC \\
\hline & & & reverse & GCCGTCACCGTTCGTTTTC \\
\hline \multirow[t]{2}{*}{$\beta$-actin } & $P C R$ & $733 \mathrm{bp}$ & forward & CCTCGCCTITGCCGATCC \\
\hline & & & reverse & GGCCATCTCTTGCTCGAAGT \\
\hline \multirow[t]{2}{*}{ GAPDH } & qPCR & $87 \mathrm{bp}$ & forward & TGCACCACCAACTGCTTAGC \\
\hline & & & reverse & GGCATGGACTGTGGTCATGAG \\
\hline
\end{tabular}



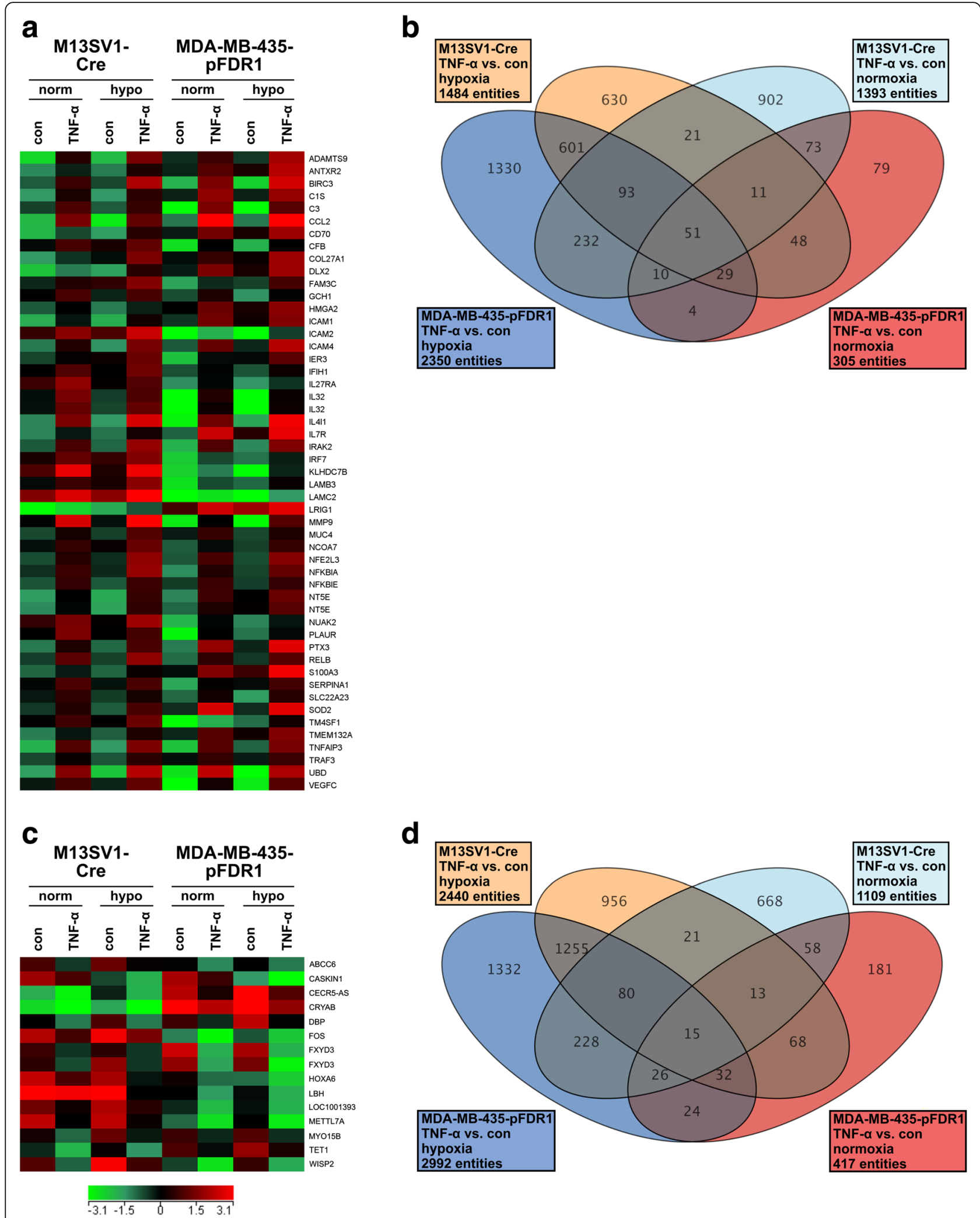

Fig. 1 (See legend on next page.) 
(See figure on previous page.)

Fig. 1 Differentially regulated genes in TNF-a-treated M13SV1-Cre and MDA-MB-435-pFDR1 cells under normoxic and hypoxic conditions. The up-regulated and down-regulated genes in TNF-a-treated cells compared with untreated cells that matched the filter criteria (flags: not detected flags and compromised spots were removed) and fold changes (2-fold up and down). a A heat map analysis of TNF-a up-regulated genes, $\mathbf{b}$ a Venn diagram of TNF-a up-regulated genes, $\mathbf{c}$ a heat map analysis of TNF-a down-regulated genes, $\mathbf{d}$ a Venn diagram of TNF-a down-regulated genes

polyclonal; Abcam, Cambridge, UK), anti-claudin-1 (mouse monoclonal; Abcam, Cambridge, UK), antiICAM1/CD54 (rabbit polyclonal; Cell Signaling, Leiden, Netherlands), $\beta$-actin (rabbit monoclonal; Cell Signaling, Leiden, Netherlands); anti-mouse-IgG-HRP-linked (Cell Signaling, Leiden, Netherlands), and anti-rabbit-IgG-HRPlinked (Cell Signaling, Leiden, Netherlands). The bands were visualized using the Pierce ECL Western blot substrate (Thermo Fisher Scientific, Bonn, Germany), according to the manufacturer's instructions, and the Aequoria Macroscopic Imaging System (Hamamatsu Photonics Germany, Herrsching am Ammersee, Germany).

\section{Zymography}

The proteolytic activity of MMP9 was measured using a gelatine zymography assay. M13SV1-Cre cells and MDA-MB-435-pFDR1 cells were plated at a density of $5 \times 10^{5}$ cells/well in a 6-well plate. After a $72 \mathrm{~h}$ incubation with $100 \mathrm{ng} / \mathrm{ml}$ TNF- $\alpha, 10 \mu \mathrm{g} / \mathrm{ml}$ minocycline, and a combination of both, the cell culture supernatants were collected and were mixed with non-reducing Laemmli sample buffer $(250 \mathrm{mM}$ Tris- $\mathrm{HCl}(\mathrm{pH} 6.8), 10 \%(w / v)$ SDS, 25\% $(v / \mathrm{v})$ glycerol, $0.01 \%(\mathrm{w} / \mathrm{v})$ bromophenol blue) without boiling. The samples were separated on a $10 \%$ sodium dodecyl sulphate polyacrylamide gel containing $0.1 \%$ gelatine (Sigma Aldrich, Taufkirchen, Germany). After separation by electrophoresis, the gels were washed four times in wash buffer $(50 \mathrm{mM}$ Tris- $\mathrm{HCl}$ (pH 7.5), $10 \mathrm{mM} \mathrm{CaCl}$, 2.5\% (v/v) Triton X-100, 0.02\% $\mathrm{NaN}_{3}$ ) for $2 \mathrm{~h}$ at room temperature to remove the SDS. Then, the gel was incubated in incubation buffer (50 mM Tris- $\mathrm{HCl}$ (pH 7.5), $150 \mathrm{mM} \mathrm{NaCl}, 10 \mathrm{mM}$ $\mathrm{CaCl}_{2}, 0.02 \% \mathrm{NaN}_{3}$ ) overnight at $37{ }^{\circ} \mathrm{C}$. Subsequently, the gel was stained with Coomassie brilliant blue R-250 (Sigma Aldrich, Taufkirchen, Germany) for $1 \mathrm{~h}$ at room temperature with gentle agitation. Finally, the gels were destained until clear bands appeared visible, which were indicative of the proteolytic activity of proteases, including MMP9.

\section{XTT assay}

To determine the appropriate minocycline concentration for the quantification of cell fusions, M13SV1-Cre and MDA-MB-435-pFDR1 cells were cultured in triplicate at a ratio of 1:3 for up to 3 days in the presence of different concentrations of minocycline. Non-treated cells served as a control. After $24 \mathrm{~h}, 48 \mathrm{~h}$, and $72 \mathrm{~h}$ the media was removed and the plates were analysed using the XTT reagent (Roche Diagnostics, Mannheim, Germany) according to the manufacturer's instructions. Absorption of the XTT-formazan derivative that formed was measured using a BioTek EL800 microplate reader (BioTek, Bad Friedrichshall, Germany).

\section{siRNA experiments}

Expression of claudin-1 was knocked-down using a specific claudin-1 siRNA (Santa Cruz Biotechnology, Heidelberg, Germany). For control purposes, a nontargeting negative control siRNA was used (QIAGEN GmbH, Hilden, Germany). M13SV1-Cre cells $\left(2.5 \times 10^{5}\right)$ were resuspended in Opti-Mem (ThermoFisher Scientific, Schwerte, Germany) and were subsequently transfected with claudin-1 siRNA or control siRNA to a final concentration of $100 \mathrm{nM}$ by lipofection (Lipofectamine ${ }^{\mathrm{max}}$ 2000; ThermoFisher Scientific, Schwerte, Germany) as described in the user's manual. The cells were seeded in serum-free MSU medium in 6-well plates. After $6 \mathrm{~h}$, the serum-free media was replaced with complete MSU medium containing FCS, antibiotics and additional supplements. The knock-down of claudin-1 expression in M13SV1-Cre cells was confirmed by Western blot.

\section{Co-immunoprecipitation}

M13SV1-Cre cells and MDA-MB-435-pFDR1 cells were stimulated with $100 \mathrm{ng} / \mathrm{ml}$ TNF- $\alpha, 10 \mu \mathrm{g} / \mathrm{ml}$ minocycline, or a combination of both, for $72 \mathrm{~h}$ at $37{ }^{\circ} \mathrm{C}$ and $5 \%$ $\mathrm{CO}_{2}$ in a humidified atmosphere. Subsequently, the cells were washed once with PBS and lysed in ice-cold lysis buffer (1\% $(v / v)$ NP-40, $50 \mathrm{mM}$ Tris- $\mathrm{HCl}(\mathrm{pH}$ 7.5), $150 \mathrm{mM} \mathrm{NaCl}, 1 \mathrm{mM}$ EDTA, $1 \mathrm{mM}$ EGTA and proteinase inhibitors (see above)) for $30 \mathrm{~min}$ on ice. The samples were sonicated three times ( $5 \mathrm{~s}$ on/20 s off) on a low pulse frequency and the total protein concentration was determined using the Pierce ${ }^{\mathrm{ma}}$ BCA Protein Assay Kit (ThermoFisher Scientific GmbH, Schwerte, Germany) according to the manufacturer's instructions. The lysates were cleared by centrifugation $(10 \mathrm{~min}$, $12,000 \mathrm{rpm})$ and the supernatants were transferred to a new tube. Prior to immunoprecipitation, the lysates were pre-treated with $25 \mu \mathrm{l}$ of Protein A Magnetic Beads (Cell Signaling, Leiden, Netherlands) for $2 \mathrm{~h}$ at $4{ }^{\circ} \mathrm{C}$ to remove any proteins that might bind non-specifically to Protein A. The samples were incubated with anti-ICAM1/CD54 (5 $\mu \mathrm{g} / \mathrm{ml}$; mouse monoclonal, clone 11C81; Bio-Techne $\mathrm{GmbH}$, Wiesbaden-Nordenstadt, Germany) or IgG1 (5 $\mu \mathrm{g} / \mathrm{ml}$; Beckman Coulter, Krefeld, Germany) overnight 
Table 2 Up-regulated genes (FC $\geq 2$ ) in TNF-a treated cells under normoxic and hypoxic conditions

\begin{tabular}{|c|c|c|c|c|c|c|}
\hline & & & Normoxia & Hypoxia & Normoxia & Hypoxia \\
\hline $\begin{array}{l}\text { Genbank } \\
\text { Accession }\end{array}$ & GeneSymbol & GeneName & $\begin{array}{l}\text { M13SV1-Cre + TNF-a } \\
\text { vs. M13SV1-Cre }\end{array}$ & $\begin{array}{l}\text { M13SV1-Cre + TNF-a } \\
\text { vs. M13SV1-Cre }\end{array}$ & $\begin{array}{l}\text { MDA-MB-435-pFDR1 + TNF-a } \\
\text { vs. MDA-MB-435-pFDR1 }\end{array}$ & $\begin{array}{l}\text { MDA-MB-435-pFDR1 + TNF-a } \\
\text { vs. MDA-MB-435-pFDR1 }\end{array}$ \\
\hline NM_182920 & ADAMTS9 & $\begin{array}{l}\text { ADAM metallopeptidase } \\
\text { with thrombospondin } \\
\text { type } 1 \text { motif, } 9\end{array}$ & 15.34 & 25.45 & 3.05 & 10.59 \\
\hline NM_058172 & ANTXR2 & anthrax toxin receptor 2 & 2.64 & 4.43 & 3.61 & 5.63 \\
\hline NM_001165 & $\mathrm{BIRC} 3$ & $\begin{array}{l}\text { baculoviral IAP repeat } \\
\text { containing } 3\end{array}$ & 4.55 & 13.11 & 23.74 & 97.65 \\
\hline NM_001734 & C1S & $\begin{array}{l}\text { complement } \\
\text { component } 1 \\
\text { s subcomponent }\end{array}$ & 5.66 & 6.97 & 6.91 & 7.03 \\
\hline NM_000064 & C3 & $\begin{array}{l}\text { complement } \\
\text { component } 3\end{array}$ & 4.31 & 4.24 & 182.13 & 115.58 \\
\hline NM_002982 & $\mathrm{CCL} 2$ & $\begin{array}{l}\text { chemokine } \\
\text { (C-C motif) ligand } 2\end{array}$ & 25.36 & 39.20 & 179.73 & 62.92 \\
\hline NM_001252 & CD70 & CD70 molecule & 3.15 & 6.99 & 4.76 & 4.52 \\
\hline NM_001710 & CFB & complement factor B & 2.41 & 2.28 & 11.21 & 5.74 \\
\hline NM_032888 & COL27A1 & $\begin{array}{l}\text { collagen, type XXVII, } \\
\text { alpha } 1\end{array}$ & 2.70 & 4.45 & 2.09 & 5.29 \\
\hline NM_004405 & DLX2 & distal-less homeobox 2 & 2.39 & 7.50 & 5.38 & 4.42 \\
\hline NM_014888 & FAM3C & $\begin{array}{l}\text { family with sequence } \\
\text { similarity } 3 \text {. member } C\end{array}$ & 2.08 & 2.50 & 3.27 & 4.06 \\
\hline NM_001024071 & $\mathrm{GCH} 1$ & GTP cyclohydrolase 1 & 2.20 & 3.07 & 2.93 & 3.83 \\
\hline NM_001300919 & HMGA2 & $\begin{array}{l}\text { high mobility group } \\
\text { AT-hook } 2\end{array}$ & 2.26 & 2.35 & 3.27 & 3.66 \\
\hline NM_000201 & ICAM1 & $\begin{array}{l}\text { intercellular adhesion } \\
\text { molecule } 1\end{array}$ & 4.46 & 6.91 & 5.76 & 3.58 \\
\hline NM_000873 & ICAM2 & $\begin{array}{l}\text { intercellular adhesion } \\
\text { molecule } 2\end{array}$ & 2.53 & 4.04 & 4.71 & 46.87 \\
\hline NM_022377 & ICAM4 & $\begin{array}{l}\text { intercellular adhesion } \\
\text { molecule } 4 \\
\text { (Landsteiner-Wiener } \\
\text { blood group) }\end{array}$ & 4.47 & 15.53 & 7.15 & 11.04 \\
\hline NM_003897 & IER3 & immediate early response 3 & 2.02 & 2.84 & 6.61 & 2.96 \\
\hline NM_022168 & $\mathrm{IFIH} 1$ & $\begin{array}{l}\text { interferon induced with } \\
\text { helicase } \mathrm{C} \text { domain } 1\end{array}$ & 2.43 & 3.47 & 2.01 & 2.48 \\
\hline NM_004843 & IL27RA & interleukin 27 receptor. Alpha & 2.65 & 2.31 & 3.47 & 2.56 \\
\hline NM_001012633 & IL32 & interleukin 32 & 4.47 & 4.23 & 45.05 & 61.04 \\
\hline NM_001012631 & IL32 & interleukin 32 & 3.53 & 5.65 & 174.41 & 103.38 \\
\hline NM_152899 & IL411 & interleukin 4 induced 1 & 13.76 & 46.63 & 50.44 & 74.89 \\
\hline NM_002185 & IL7R & interleukin 7 receptor & 2.81 & 3.65 & 23.52 & 8.37 \\
\hline NM_001570 & IRAK2 & $\begin{array}{l}\text { interleukin-1 receptor-associated } \\
\text { kinase } 2\end{array}$ & 5.28 & 13.66 & 14.76 & 14.90 \\
\hline NM_004031 & IRF7 & interferon regulatory factor 7 & 2.30 & 2.31 & 4.20 & 2.17 \\
\hline NM_138433 & $\mathrm{KLHDC7B}$ & kelch domain containing $7 \mathrm{~B}$ & 5.74 & 10.45 & 2.77 & 13.77 \\
\hline NM_001017402 & LAMB3 & laminin, beta 3 & 2.12 & 3.48 & 5.68 & 2.89 \\
\hline NM_005562 & LAMC2 & laminin, gamma 2 & 2.73 & 4.65 & 2.05 & 4.42 \\
\hline NM_015541 & LRIG1 & $\begin{array}{l}\text { leucine-rich repeats and } \\
\text { immunoglobulin-like domains } 1\end{array}$ & 2.29 & 2.49 & 4.45 & 2.27 \\
\hline NM_004994 & MMP9 & $\begin{array}{l}\text { matrix metallopeptidase } 9 \\
\text { (gelatinase B, } 92 \mathrm{kDa} \text { gelatinase, } \\
92 \mathrm{kDa} \text { type IV collagenase) }\end{array}$ & 11.45 & 27.25 & 13.49 & 44.92 \\
\hline NM_018406 & MUC4 & mucin 4, cell surface associated & 2.49 & 4.72 & 2.34 & 2.76 \\
\hline NM_181782 & NCOA7 & nuclear receptor coactivator 7 & 2.08 & 2.89 & 2.14 & 3.31 \\
\hline NM_004289 & NFE2L3 & nuclear factor. Erythroid 2-like 3 & 3.08 & 7.27 & 5.00 & 8.99 \\
\hline NM_020529 & NFKBIA & & 2.97 & 7.63 & 5.41 & 5.74 \\
\hline
\end{tabular}


Table 2 Up-regulated genes (FC $\geq 2$ ) in TNF-a treated cells under normoxic and hypoxic conditions (Continued)

\begin{tabular}{|c|c|c|c|c|c|c|}
\hline & & & Normoxia & Hypoxia & Normoxia & Hypoxia \\
\hline $\begin{array}{l}\text { Genbank } \\
\text { Accession }\end{array}$ & GeneSymbol & GeneName & $\begin{array}{l}\text { M13SV1-Cre + TNF-a } \\
\text { vs. M13SV1-Cre }\end{array}$ & $\begin{array}{l}\text { M13SV1-Cre + TNF-a } \\
\text { vs. M13SV1-Cre }\end{array}$ & $\begin{array}{l}\text { MDA-MB-435-pFDR1 + TNF-a } \\
\text { vs. MDA-MB-435-pFDR1 }\end{array}$ & $\begin{array}{l}\text { MDA-MB-435-pFDR1 + TNF-a } \\
\text { vs. MDA-MB-435-pFDR1 }\end{array}$ \\
\hline & & $\begin{array}{l}\text { nuclear factor of kappa light } \\
\text { polypeptide gene enhancer in } \\
\text { B-cells inhibitor, alpha }\end{array}$ & & & & \\
\hline NM_004556 & NFKBIE & $\begin{array}{l}\text { nuclear factor of kappa light } \\
\text { polypeptide gene enhancer } \\
\text { in B-cells inhibitor, epsilon }\end{array}$ & 3.86 & 4.40 & 3.41 & 3.14 \\
\hline NM_002526 & NT5E & 5'-nucleotidase, ecto (CD73) & 4.37 & 9.64 & 7.12 & 3.26 \\
\hline NM_002526 & NT5E & 5'-nucleotidase, ecto (CD73) & 3.37 & 8.28 & 3.62 & 2.54 \\
\hline NM_030952 & NUAK2 & NUAK family, SNF1-like kinase. 2 & 2.24 & 5.48 & 5.71 & 2.87 \\
\hline NM_001005377 & PLAUR & $\begin{array}{l}\text { plasminogen activator, } \\
\text { urokinase receptor }\end{array}$ & 4.00 & 2.12 & 14.94 & 2.74 \\
\hline NM_002852 & PTX3 & pentraxin 3 , long & 4.37 & 6.10 & 16.59 & 17.75 \\
\hline NM_006509 & RELB & $\begin{array}{l}\text { v-rel avian reticuloendotheliosis } \\
\text { viral oncogene homolog B }\end{array}$ & 5.02 & 8.99 & 4.61 & 4.41 \\
\hline NM_002960 & S100A3 & $\begin{array}{l}\text { S100 calcium binding } \\
\text { protein A3 }\end{array}$ & 2.01 & 2.88 & 4.90 & 7.84 \\
\hline NM_001002236 & SERPINA1 & $\begin{array}{l}\text { serpin peptidase inhibitor, } \\
\text { clade A (alpha-1 antiproteinase. } \\
\text { antitrypsin), member } 1\end{array}$ & 2.50 & 2.73 & 5.44 & 2.35 \\
\hline NM_015482 & SLC22A23 & $\begin{array}{l}\text { solute carrier family } 22, \\
\text { member } 23\end{array}$ & 2.08 & 2.23 & 3.21 & 7.09 \\
\hline NM_001024465 & SOD2 & $\begin{array}{l}\text { superoxide dismutase } 2, \\
\text { mitochondrial }\end{array}$ & 2.48 & 5.20 & 16.52 & 19.28 \\
\hline NM_014220 & TM4SF1 & $\begin{array}{l}\text { transmembrane } 4 \mathrm{~L} \text { six } \\
\text { family member } 1\end{array}$ & 2.08 & 3.23 & 5.34 & 3.43 \\
\hline NM_017870 & TMEM132A & transmembrane protein $132 \mathrm{~A}$ & 2.63 & 3.35 & 3.74 & 3.53 \\
\hline NM_006290 & TNFAIP3 & $\begin{array}{l}\text { tumor necrosis factor, } \\
\text { alpha-induced protein } 3\end{array}$ & 14.81 & 16.94 & 19.45 & 9.77 \\
\hline NM_145725 & TRAF3 & TNF receptor-associated factor 3 & 2.21 & 3.61 & 2.02 & 2.50 \\
\hline NM_006398 & UBD & ubiquitin $\mathrm{D}$ & 19.59 & 58.56 & 100.44 & 226.21 \\
\hline NM_005429 & VEGFC & $\begin{array}{l}\text { vascular endothelial } \\
\text { growth factor C }\end{array}$ & 2.76 & 4.16 & 74.91 & 33.90 \\
\hline
\end{tabular}

at $4{ }^{\circ} \mathrm{C}$. Thereafter, $30 \mu \mathrm{l}$ of Protein A Magnetic Beads were added and the samples were incubated for an additional $2 \mathrm{~h}$ at $4{ }^{\circ} \mathrm{C}$. The precipitates were washed three times in lysis buffer, separated on a magnetic rack and resuspended in $3 \times$ Laemmli Sample Buffer (with DTT, without $\beta$-mercaptoethanol). ICAM1/CD54 and the co-immunoprecipitated proteins were detected by Western blot.

\section{Soluble ICAM1 detection}

To detect soluble ICAM1, the cell culture supernatants from TNF- $\alpha$-treated, minocycline-treated, and TNF- $\alpha$ and minocycline-treated M13SV1-Cre cells and MDAMB-435-pFDR1 cells were collected and concentrated using Vivaspin-2 centrifugal concentrators $(100,000$ MWCO; Sartorius, Göttingen, Germany). The total protein concentration of the concentrated supernatants was determined using the Pierce ${ }^{\mathrm{Tx}}$ BCA Protein Assay Kit (ThermoFisher Scientific GmbH, Schwerte, Germany) according to the manufacturer's instructions. An equal amount of supernatant from each sample was resuspended in Laemmli sample buffer. Soluble ICAM1 was detected by Western blot using an anti-ICAM1/CD54 antibody (clone 14C11, mouse monoclonal; ThermoFisher Scientific GmbH, Schwerte, Germany).

\section{Statistical analyses}

The statistical significance of the data presented in Fig. 2 was calculated using an unpaired, two-tailed Student's $t$ test. The mean differences of the data presented in Figs. 4, 5, 6 and 7 were tested by ANOVA F-tests. Afterwards, multiple comparisons were performed using Scheffé post-hoc tests. Statistical analyses were performed using SPSS Version 23.0.0.2 and $p$-values $<0.05$ were considered significant.

\section{Language editing}

The manuscript was language edited by American Journal Experts (Durham, NC, USA). 
Table 3 Down-regulated genes (FC $\leq-2$ ) in TNF-a treated cells under normoxic and hypoxic conditions

\begin{tabular}{|c|c|c|c|c|c|c|}
\hline & & & Normoxia & Hypoxia & Normoxia & Hypoxia \\
\hline $\begin{array}{l}\text { Genbank } \\
\text { Accession }\end{array}$ & GeneSymbol & GeneName & $\begin{array}{l}\text { M13SV1-Cre + } \\
\text { TNF-a vs. } \\
\text { M13SV1-Cre }\end{array}$ & $\begin{array}{l}\text { M13SV1-Cre + } \\
\text { TNF-a vs. } \\
\text { M13SV1-Cre }\end{array}$ & $\begin{array}{l}\text { MDA-MB-435-pFDR1 + } \\
\text { TNF-a vs. MDA-MB-435- } \\
\text { pFDR1 }\end{array}$ & $\begin{array}{l}\text { MDA-MB-435-pFDR1 + } \\
\text { TNF-a vs. MDA-MB-435- } \\
\text { pFDR1 }\end{array}$ \\
\hline NM_001079528 & ABCC6 & $\begin{array}{l}\text { ATP-binding cassette, } \\
\text { sub-family C (CFTR/MRP), } \\
\text { member } 6\end{array}$ & -2.72 & -2.26 & -2.51 & -2.36 \\
\hline NM_020764 & CASKIN1 & CASK interacting protein 1 & -2.03 & -2.26 & -2.52 & -7.21 \\
\hline NR_024482 & CECR5-AS1 & CECR5 antisense RNA 1 & -2.10 & -2.94 & -3.66 & -6.97 \\
\hline NM_001885 & CRYAB & crystallin, alpha B & -2.76 & -4.62 & -2.03 & -6.23 \\
\hline NM_001352 & DBP & $\begin{array}{l}\text { D site of albumin promoter } \\
\text { (albumin D-box) binding protein }\end{array}$ & -2.36 & -4.44 & -2.20 & -4.92 \\
\hline NM_005252 & FOS & $\begin{array}{l}\text { FBJ murine osteosarcoma } \\
\text { viral oncogene homolog }\end{array}$ & -2.45 & -2.72 & -3.24 & -2.60 \\
\hline NM_001136007 & FXYD3 & $\begin{array}{l}\text { FXYD domain containing } \\
\text { ion transport regulator } 3\end{array}$ & -2.32 & -2.06 & -19.31 & -14.74 \\
\hline NM_001136008 & FXYD3 & $\begin{array}{l}\text { FXYD domain containing } \\
\text { ion transport regulator } 3\end{array}$ & -2.44 & -4.64 & -10.82 & -19.67 \\
\hline XM_006715716 & HOXA6 & homeobox A6 & -2.75 & -4.61 & -2.38 & -2.30 \\
\hline NM_030915 & $\mathrm{LBH}$ & $\begin{array}{l}\text { limb bud and } \\
\text { heart development }\end{array}$ & -2.03 & -31.03 & -2.93 & -3.35 \\
\hline NR_024485 & LOC100130093 & $\begin{array}{l}\text { uncharacterized } \\
\text { LOC100130093 }\end{array}$ & -2.28 & -3.05 & -3.11 & -3.30 \\
\hline NM_014033 & METTL7A & methyltransferase like $7 \mathrm{~A}$ & -4.74 & -4.34 & -2.93 & -6.66 \\
\hline BC128044 & MYO15B & myosin XVB pseudogene & -2.42 & -2.81 & -2.15 & -2.70 \\
\hline NM_030625 & TET1 & $\begin{array}{l}\text { tet methylcytosine } \\
\text { dioxygenase } 1\end{array}$ & -2.90 & -3.02 & -2.01 & -2.70 \\
\hline NM_003881 & WISP2 & $\begin{array}{l}\text { WNT1 inducible signaling } \\
\text { pathway protein } 2\end{array}$ & -3.96 & -4.69 & -3.99 & -5.53 \\
\hline
\end{tabular}

\section{Results}

Analysis of the gene expression pattern of M13SV1-Cre cells and MDA-MB-435-pFDR1 cells with TNF- $a$ treatment in normoxic and hypoxic conditions

We recently demonstrated that the fusion of human M13SV1-Cre breast epithelial cells and human MDAMB-435-pFDR1 breast cancer cells under normoxic and hypoxic conditions is positively triggered by TNF- $\alpha$ [18]. To analyse the changes in the gene expression profile of both cell lines induced by TNF- $\alpha$ (100 ng/ml) under normoxic and hypoxic conditions, cDNA-microarray studies were performed. In total, 51 genes were found to be significantly up-regulated in TNF- $\alpha$-treated cell lines under both normoxia and hypoxia (Fig. 1a, b; Table 2), including adhesion molecules such as ICAM1, ICAM2, and ICAM4, components of the extracellular matrix, including COL27A1, LAMB3, LAMC2, and MUC4, chemokines, growth factors, and interleukins, such as CCL2, VEGFC and IL32, and proteases including ADAMTS9 and MMP9 (Fig. 1; Table 2). In particular, CCL2, MMP9 and ICAM1 have already been associated with cell fusion $[9,28]$. In contrast, 15 genes were downregulated in TNF- $\alpha$-treated cells under normoxic and hypoxic conditions, such as ABCC6 and FOS (Fig. 1c, d; Table 3).

\section{Validation of microarray data by QPCR and conventional PCR}

To validate the microarray data, Claudin-1 (CLDN1), ICAM1, and MMP9 expression was analysed by qPCR and ADAMTS9, CCL2, IL4I1, IL7R, TNFAIP3 and VEGFC expression was analysed by conventional PCR. CLDN1 did not pass the filter criteria but the microarray data revealed a marked up-regulation of this protein in TNF- $\alpha$-treated (100 ng/ml) MDA-MB-435-pFDR1 cells under normoxic and hypoxic conditions (Additional file 1). The qPCR and conventional PCR data partially matched the microarray data (Fig. 2a, d). The microarray data revealed an up-regulation of ICAM1 expression in TNF- $\alpha$-stimulated (100 ng/ml) M13SV1-Cre cells under normoxic conditions (Fig. 1; Table 2), which was opposite to the qPCR data showing similar ICAM1 mRNA levels in untreated and TNF- $\alpha$-treated M13SV1Cre cells under normoxic conditions (Fig. 2b). In contrast, ICAM1 was up-regulated in TNF- $\alpha$-stimulated M13SV1-Cre cells under hypoxia (Fig. 1; Table 2), which 

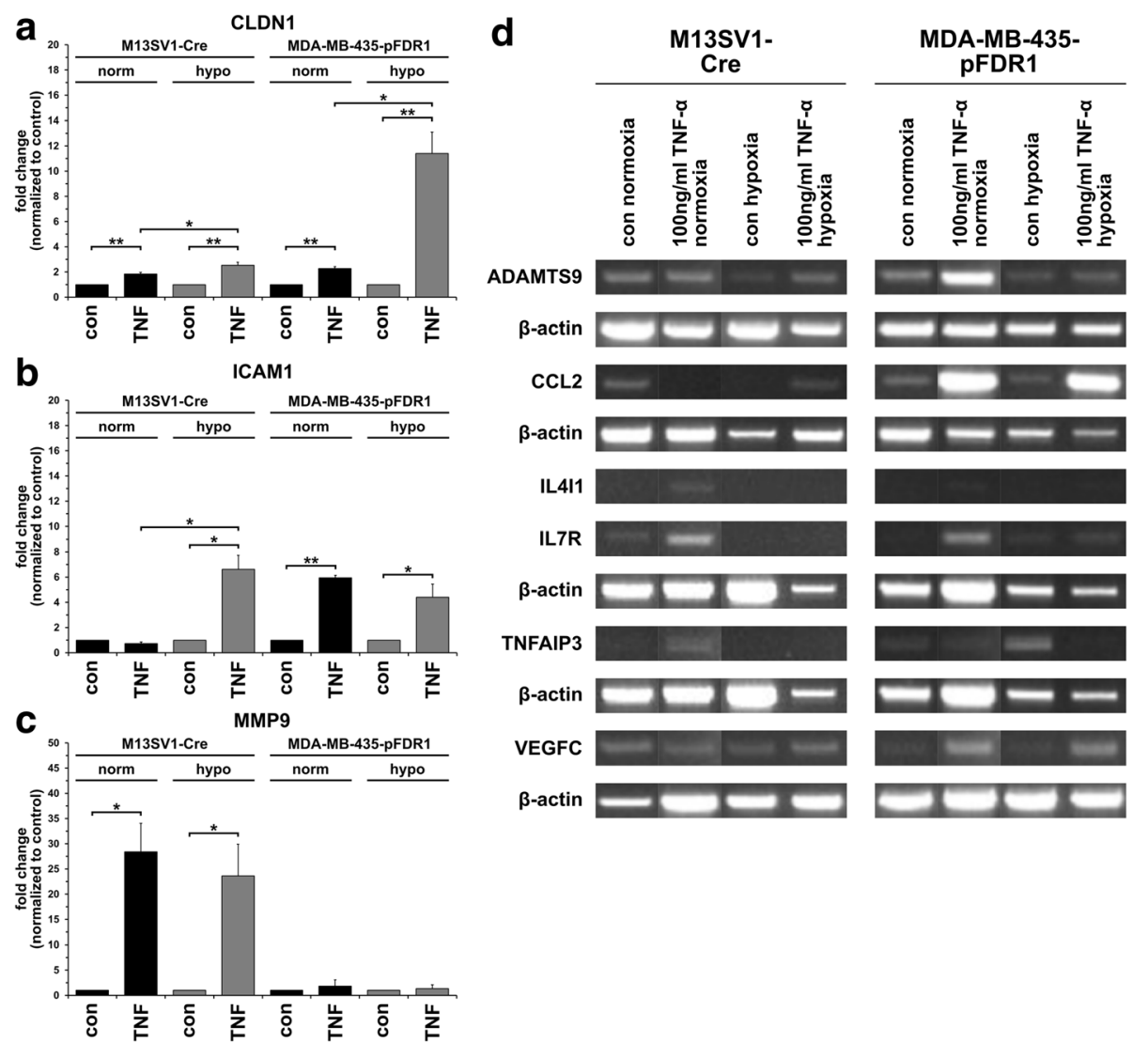

Fig. 2 Validation of microarray data by qPCR and conventional PCR. a qPCR CLDN1, b qPCR ICAM1, c qPCR MMP9, d conventional PCR. MMP9 was significantly up-regulated in TNF-a-treated (100 ng/ml) M13SV1-Cre cells, whereas significantly elevated CLDN1 and ICAM1 expression levels were detected in TNF-a-treated (100 ng/ml) MDA-MB-435-pFDR1 cells. Likewise, increased CCL2 and VEGFC expression levels were detected in TNF-a-treated $(100 \mathrm{ng} / \mathrm{ml})$ MDA-MB-435-pFDR1 cells. Data are presented as the mean \pm SD of at least three independent experiments (a) or the representative data of three independent experiments $(\mathbf{b})$. Statistical analysis: unpaired, two-tailed Student's $t$-test: ${ }^{*}=p<0.05 ;{ }^{* *}=p<0.01$

could be validated by qPCR (Fig. 2b). The TNF- $\alpha-$ induced increase in CLDN1 and MMP9 expression in M13SV1-Cre cells under normoxia and hypoxia (Fig. 1; Table 2) were validated by qPCR, whereas MMP9 mRNA expression was markedly up-regulated in TNF$\alpha$-stimulated cells (Fig. 2c). For MDA-MB-435-pFDR1 cells, only the microarray data for CLDN1 and ICAM1 could be validated by qPCR; the qPCR data for MMP9 did not match the microarray data (Figs. 1, 2c; Table 2). Markedly increased MMP9 expression levels were determined for TNF- $\alpha$-stimulated MDA-MB-435-pFDR1 cells (Fig. 1; Table 2), which is opposite to qPCR rather showing comparable MMP9 mRNA expression levels in untreated and TNF- $\alpha$ treated cells (Fig. 2c).

CCL2, IL7R1, and VEGFC expression levels were partially up-regulated in TNF- $\alpha$-stimulated MDA-MB-435-pFDR1 cells, which agreed with the microarray data (Fig. 1, 2b; Table 2). In contrast, the microarray data revealed an upregulation of IL4I1 in TNF- $\alpha$-treated MDA-MB-435pFDR1 cells, which could not be validated by conventional PCR (Fig. 2d). Instead, only a weak PCR product was observed in TNF- $\alpha$-stimulated MDA-MB-435-pFDR1 cells under normoxic conditions, whereas under hypoxia no PCR product was detected (Fig. 2 d). TNF- $\alpha$ induced an increase in IL4I1, IL7R and TNFAIP3 expression in M13SV1-Cre cells under normoxic conditions (Fig. 2d) and in hypoxic conditions there was only a slight increase in VEGFC levels in response to TNF- $\alpha$ treatment (Fig. 2d). Hence, the M13SV1-Cre microarray data were only partially validated by conventional PCR (Figs. 1, 2d; Table 2).

\section{Validation of the microarray data by western blot}

To further validate the microarray and PCR data, Western blot analyses were conducted for CCL2, CLDN1, ICAM1 and MMP9. TNF- $\alpha$-induced $(100 \mathrm{ng} / \mathrm{ml})$ CCL2 expression was observed in MDA-MB-435-pFDR1 cells with higher CCL2 expression under normoxia compared with hypoxia (Fig. 3a). In contrast, no CCL2 expression was found in M13SV1-Cre human breast epithelial cells (Fig. 3a), which agrees with conventional PCR data (Fig. 2b). The expression of CLDN1 was only observed in M13SV1-Cre cells concomitant with 


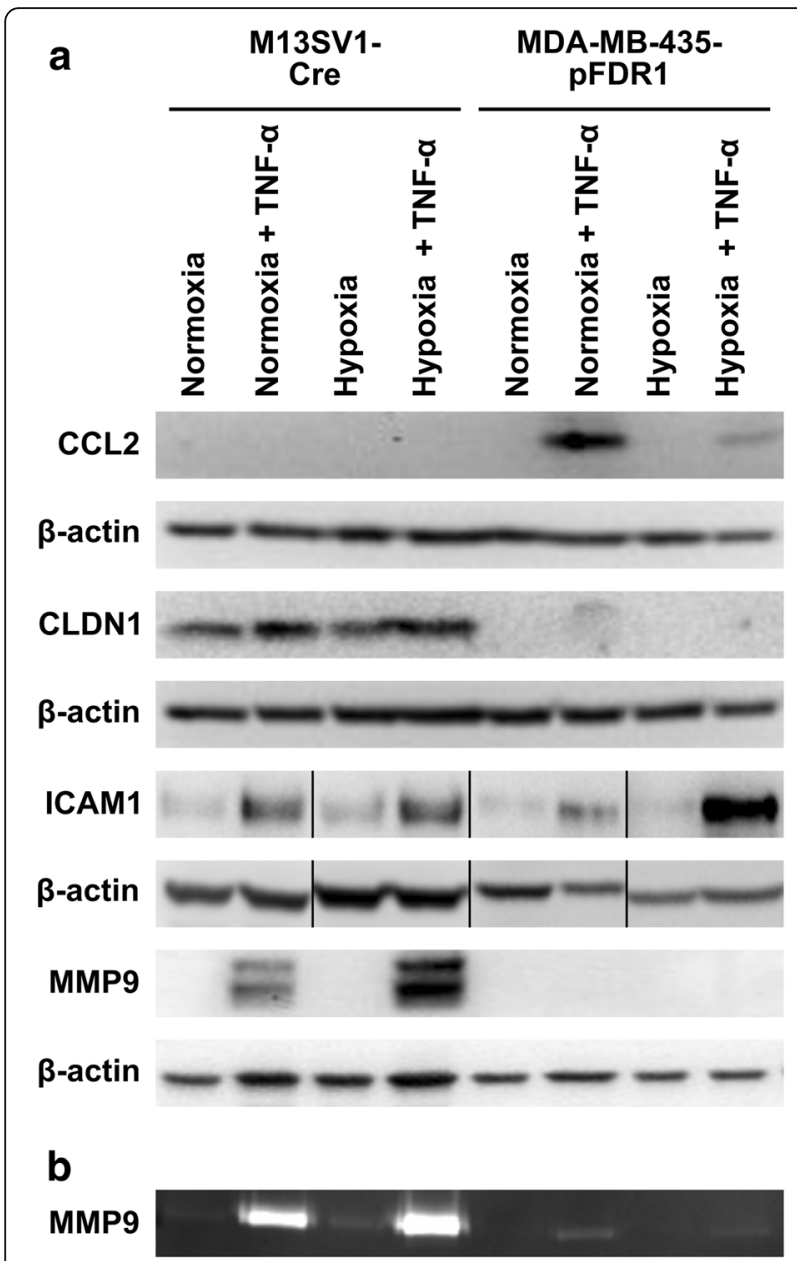

Fig. 3 Validation of qPCR and conventional RT-PCR data by Western blot and zymography. a Western blot analysis: CCL2 protein expression was only detected in TNF-a-treated (100 ng/ml) MDA-MB-435-pFDR1 cells, whereas CLDN1 expression was absent from these cells but was clearly detectable in M13SV1-Cre cells. Increased ICAM1 expression was observed in TNF-a-treated cells, whereas increased MMP9 expression was only found in TNF-a-stimulated M13SV1-Cre cells. Two discrete bands were detected for MMP9 in Western blot analysis; the upper band represents inactive MMP9 and the lower band represents active MMP9. ICAM1 Western blot data were rearranged because ICAM1 samples were originally loaded in a different order. b Zymography: markedly increased MMP9 expression levels and activity were detected in TNF-a-treated M13SV1-Cre cells, whereas even in TNF-a-stimulated MDA-MB-435 cells slightly enhanced MMP9 expression levels could be identified. The data shown are representative of at least three independent experiments

slightly increased CLDN1 levels in the presence of TNF- $\alpha$ (Fig. 3a), which is similar to qPCR data (Fig. 2). Interestingly, no CLDN1 protein expression was detected in MDA-MB-435-pFDR1 cells (Fig. 3a) even though qPCR data revealed increased CLDN1 mRNA levels in TNF- $\alpha$-treated cells (Fig. 2b). In agreement with the microarray data (Fig. 1; Table 2), but opposite to the qPCR data (Fig. 2a), increased ICAM1 protein expression was identified in TNF- $\alpha$-treated M13SV1-Cre cells (Fig. 3a). Increased TNF- $\alpha$-induced MMP9 levels were only observed in M13SV1-Cre cells (Fig. 3a), which agreed with the qPCR data (Fig. 2c). In addition to Western blot analysis, MMP9 expression was further analysed by zymography, which also showed increased MMP9 expression in TNF- $\alpha$-treated M13SV1-Cre cells (Fig. 3b). Zymography analysis revealed a slight up-regulation of MMP9 expression in TNF- $\alpha$-stimulated MDA-MB-435-pFDR1 cells (Fig. $3 b$ ), which confirmed the qPCR data showing a weak MMP9 PCR product in TNF- $\alpha$-treated cells under normoxic conditions (Fig. 2c).

Fusion of M13SV1-Cre cells and MDA-MB-435-pFDR1 cells is impaired by the inhibition of MMP9

To investigate whether CLDN1, ICAM1 and MMP9 might be involved in the TNF- $\alpha$-induced fusion of M13SV1-Cre and MDA-MB-435-pFDR1 cells, the expression of these proteins was blocked. The knockdown of CLDN1 with siRNA in M13SV1-Cre cells did not impair the TNF- $\alpha$-induced fusion of the cells (Fig. 4a) even though the siRNA-mediated downregulation of CLDN1 expression in M13SV1-Cre was stable for at least 3 days (Fig. 4b). Interestingly, compared with M13SV1-Cre cells that were transfected with scrambled siRNA, M13SV1-Cre cells transfected with CLDN1 siRNA had a slightly increased fusion rate (Fig. 4a).

The inhibition of ICAM1 function with a blocking ICAM1 antibody was not correlated with a decreased TNF- $\alpha$-induced rate of the fusion of M13SV1-Cre and MDA-MB-435-pFDR1 cells (Fig. 4c). In contrast, the inhibition of MMP9 function using the specific inhibitor SB-3CT was associated with a dose-dependent, impaired, TNF- $\alpha$-induced cell fusion rate of M13SV1-Cre and MDA-MB-435-pFDR1 cells (Fig. 4d).

\section{The TNF- $a$-induced fusion of M13SV1-Cre and MDA-MB-}

435-pFDR1 cells is inhibited by minocycline

The tetracycline based antibiotic minocycline was tested because of its capability to down-regulate MMP9 expression in cells $[29,30]$. First, XTT proliferation studies were performed to determine the optimal minocycline concentration and a range between $5 \mu \mathrm{g} / \mathrm{ml}$ and $24 \mu \mathrm{g} / \mathrm{ml}$ was tested. Prolonged cultivation of M13SV1-Cre and MDA-MB-435-pFDR1 cells with increasing concentrations of minocycline was correlated to a decreased cell proliferation rate (Additional file 2). Hence, for on-going studies, a minocycline concentration of $10 \mu \mathrm{g} / \mathrm{ml}$ was chosen and only the impact of minocycline under normoxic conditions was analysed. The cultivation of cells under hypoxia and in the presence of $10 \mu \mathrm{g} / \mathrm{ml}$ minocycline was associated with numbers of dead cells 

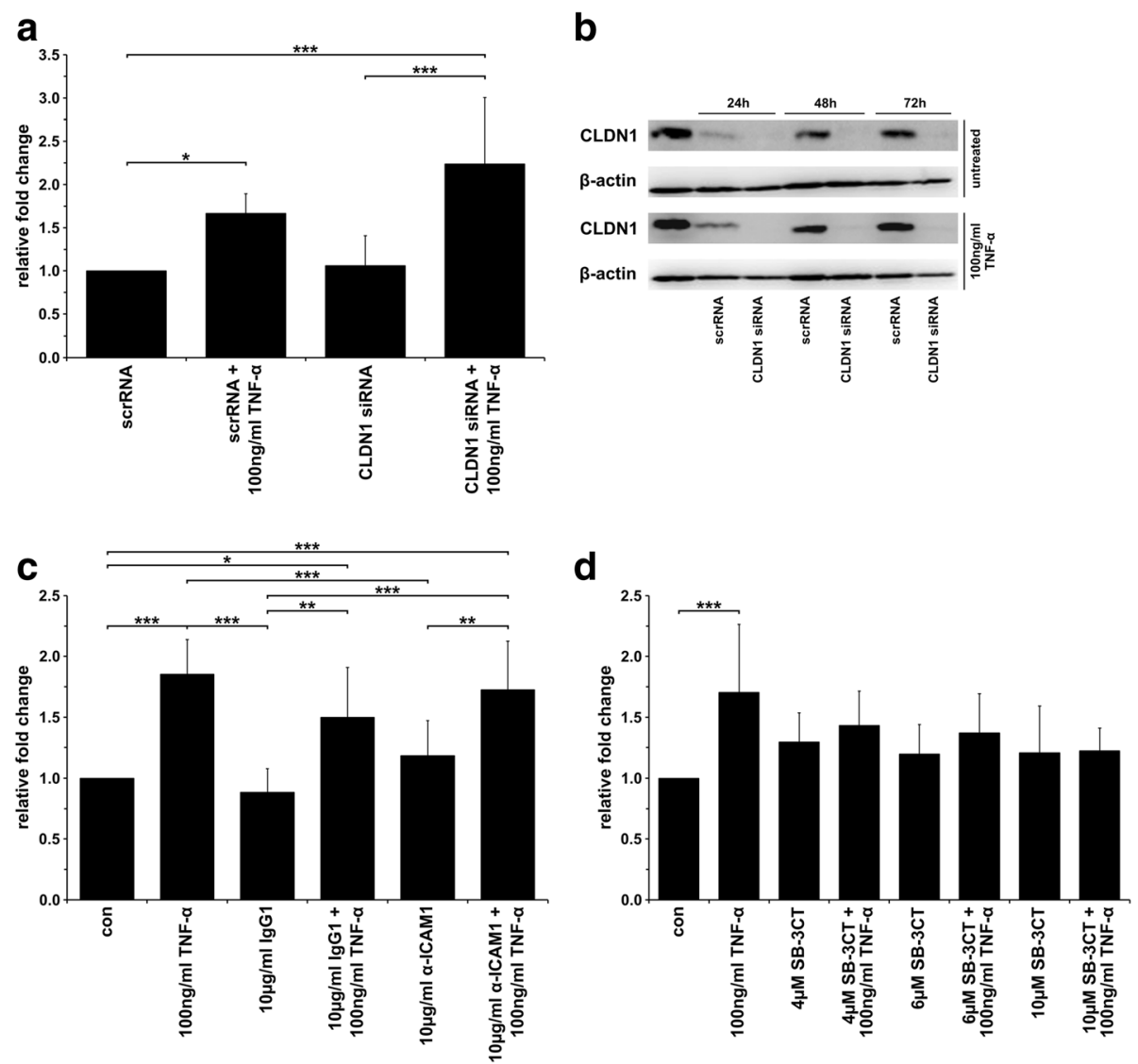

Fig. 4 TNF-a-induced cell fusion could be blocked by the inhibition of MMP9. a The knockdown of CLDN1 expression with specific siRNA was not correlated with a decreased TNF-a-induced $(100 \mathrm{ng} / \mathrm{ml})$ fusion rate. $\mathbf{b}$ siRNA-mediated CLDN1 expression levels of M13SV1-Cre cells were stably down-regulated over $72 \mathrm{~h}$. c Inhibition of ICAM1 activity using a blocking antibody did not impair the TNF-a-induced fusion between M13SV1-Cre and MDA-MB-435-pFDR1 cells. $\mathbf{d}$ The TNF-a-induced fusion of M13SV1-Cre and MDA-MB-435-pFDR1 cells was impaired by the MMP9 inhibitor SB-3CT in a dose-dependent manner. The mean \pm SD of at least three independent experiments is shown. Statistical analysis: ANOVA F-test and Scheffé post-hoc test: ${ }^{*}=p<0.05 ;{ }^{* *}=p<0.01 ;{ }^{* *}=p<0.001$

that were too high to perform further cell fusion quantification studies.

The incubation of cells with $5 \mu \mathrm{g} / \mathrm{ml}$ or $10 \mu \mathrm{g} / \mathrm{ml}$ minocycline was correlated to a dose-dependent decreased TNF- $\alpha$-induced fusion rate (Fig. 5), whereas the spontaneous fusion rate of the cells remained unaffected in the presence of different minocycline concentrations (Fig. 5).

\section{Effect of minocycline on CLDN1, ICAM1, and MMP9 expression}

Quantitative PCR and Western blot data showed that CLDN1 and ICAM1 expression in TNF- $\alpha$-treated and TNF- $\alpha$ and minocycline-treated M13SV1-Cre cells were comparable (Fig. 6a, b). In contrast, the qPCR results showed significantly reduced MMP9 expression in M13SV1-Cre cells co-treated with TNF- $\alpha$ and minocycline as compared with TNF- $\alpha$-treated cells (Fig. 6c), which was further validated by zymography (Fig. 6c). MMP9 protein expression was slightly increased in TNF- $\alpha+$ minocycline co-treated M13SV1-Cre cells compared with TNF- $\alpha$-stimulated cells (Fig. 6c). This (reproducible) result remains ambiguous as did the finding that significantly higher MMP9 mRNA levels were observed in minocycline treated M13SV1-Cre cells (Fig. 6c) although increased MMP9 protein expression levels were not detected (Fig. 6c).

In contrast to M13SV1-Cre breast epithelial cells, neither CLDN1 nor MMP9 protein expression was detected in MDA-MB-435-pFDR1 cells (Fig. 6a, c). Because very weak MMP9 bands were observed in MDA-MB-435pFDR1 cells by zymography (Fig. 6c), and MMP9 and CLDN1 were detected by qPCR (Fig. 6a, c) we assume that MMP9 and CLDN1 protein expression levels were below the detection threshold of the antibodies that were used. Minocycline treatment increased MMP9 mRNA expression in both M13SV1-Cre cells and MDA-MB-435pFDR1 cells (Fig. 6c), which, however, did not get translated into increased expression of the subsequent proteins (Fig. 6c). Compared with M13SV1-Cre breast epithelial cells, increased ICAM1 expression levels were found in 


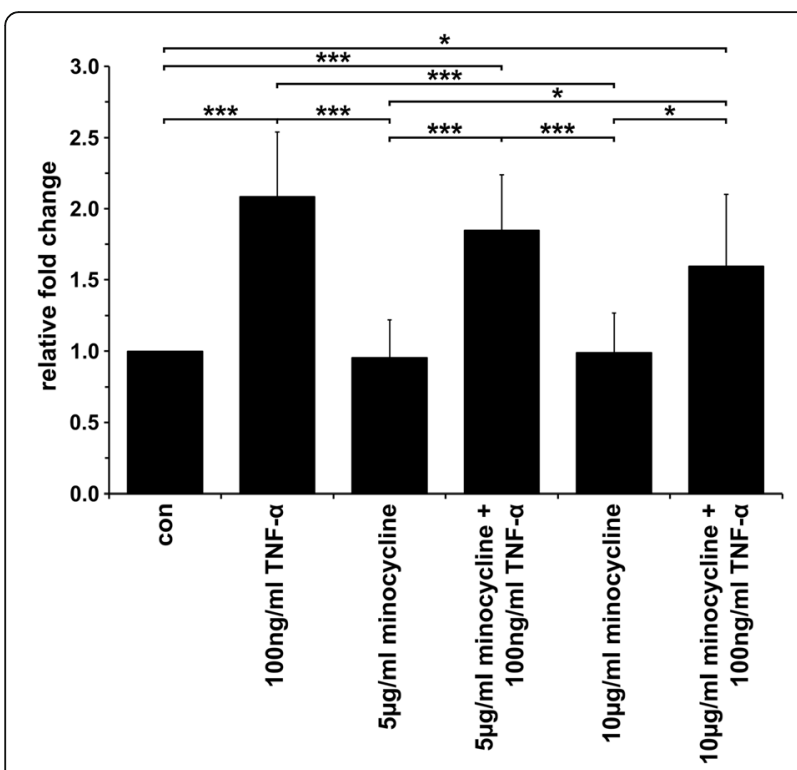

Fig. 5 TNF-a-induced fusion was inhibited by the tetracycline-based antibiotic minocycline. TNF-a-induced $(100 \mathrm{ng} / \mathrm{ml})$ cell fusion was impaired by minocycline in a dose-dependent manner. The data shown are the mean \pm SD of three independent experiments. Statistical analysis: ANOVA F-test and Scheffé post-hoc test: ${ }^{*}=p<0.05$; ${ }^{* *}=p<0.01 ; * * * 0.001$

TNF- $\alpha$ - and TNF- $\alpha+$ minocycline-treated MDA-MB435-pFDR1 cells (Fig. 6b). Interestingly, significantly higher ICAM1 mRNA and protein levels were detected in the TNF- $\alpha+$ minocycline-treated MDA-MB-435-pFDR1 cells than in the TNF- $\alpha$-stimulated cells (Fig. $6 \mathrm{~b}$ ).

Co-immunoprecipitation assays were performed to investigate whether MMP9 bound to ICAM1 and whether this would be correlated to increased soluble ICAM1 (sICAM1) levels because of MMP9-dependent proteolytic degradation [31]. As shown in Fig. 6d, MMP9 could be coimmunoprecipitated with ICAM1 in M13SV1-Cre cells but not in MDA-MB-435-pFDR1 cells. Higher ICAM1 and MMP9 levels were co-immunoprecipitated in TNF- $\alpha-$ stimulated M13SV1-Cre cells, whereas lower levels were detected in cells co-treated with TNF- $\alpha$ and minocycline (Fig. 6d), which is in agreement with the Western blot data (Fig. 6c). In contrast, because of rather low MMP9 expression levels in MDA-MB-435-pFDR1 cells, MMP9 was not co-immunoprecipitated. To prove, whether the bindings of ICAM1 were proteolytically degraded by MMP9, the supernatants from cell culture were collected. Western blot analysis revealed no differences in the relative amount of sICAM1 monomers and dimers between the control cells and those treated with TNF- $\alpha$ or TNF- $\alpha+$ minocycline.

\section{Both minocycline and the MMP9 inhibitor SB-3CT impaired TNF-a-mediated cell fusion}

The fusion rate of cells co-treated with both minocycline and SB-3CT (and TNF- $\alpha$ ) was comparable to that of cells treated with minocycline and minocycline + TNF$\alpha$, respectively, and no additive effect was observed (Fig. 7). Interestingly, the cultivation of cells in the presence of both minocycline and the blocking ICAM1 antibody yielded in an increased cell fusion rate, which was more intense in the presence of TNF- $\alpha$ (Fig. 7). Even though the data were not significant, the findings were reproducible in independent experiments, indicating that the increased fusion rate of cells in the presence of minocycline and anti-ICAM1 (and TNF- $\alpha$ ) is a true effect.

\section{Discussion}

In a previous study we demonstrated that the proinflammatory cytokine TNF- $\alpha$ is a potent trigger of cell fusion between human M13SV1-Cre breast epithelial cells and human breast cancer cell lines under both normoxic and hypoxic conditions [18]. Here, we investigated the impact of TNF- $\alpha$ on the gene expression profiles of M13SV1-Cre and MDA-MB-435-pFDR1 cells to identify which of the differentially-regulated genes might be involved in cell fusion. Of the identified target genes, only the inhibition of MMP9 was correlated with a decreased TNF- $\alpha$-induced cell fusion rate.

Here, we used the MDA-MB-435 cancer cell line, whose origin is debated to be either breast cancer or melanoma. A systematic analysis of the gene expression profiles of 60 human cancer cell lines first revealed that MDA-MB-435 cells express genes that are highly expressed in most melanoma-derived cell lines, suggesting that this cell line originated from melanoma rather than breast cancer [32]. This assumption was further supported by comparative genomic hybridisation (VGH) and microsatellite polymorphism analyses showing that MDA-MB-435 cells and M14 cells share similarities [33]. In contrast, MDA-MB-435 and M14 cells markedly differed in their DNA methylation profiles; more hypermethylated CpG islands were detected in MDA-MB-435 cells than in M14 cells and MDA-MB-435 cells were not grouped with melanoma cells after a hierarchical cluster analysis [34]. Likewise, the phenotypic and molecular characterisation of MDA-MB-435 cells further revealed similarities to other breast cancer cell lines, such as MDA-MB-231, SUM1315 or HBL100 cells, which belong to the claudin-low intrinsic subtype of breast cancer [35].

PCR data showed that the microphthalmia-associated transcription factor (MITF), which is a lineage survival oncogene amplified in malignant melanoma cell lines, was expressed in MDA-MB-435 cells [36, 37]. However, MITF protein was not expressed in MDA-MB-435 cells [38] but mRNA expression was detected in other breast cancer cell lines, such as MCF-10A, MCF-7, SKBR3, and U87 and D54 glioblastoma cell lines [37]. The coexpression of neuronal, epithelial and melanocytic 


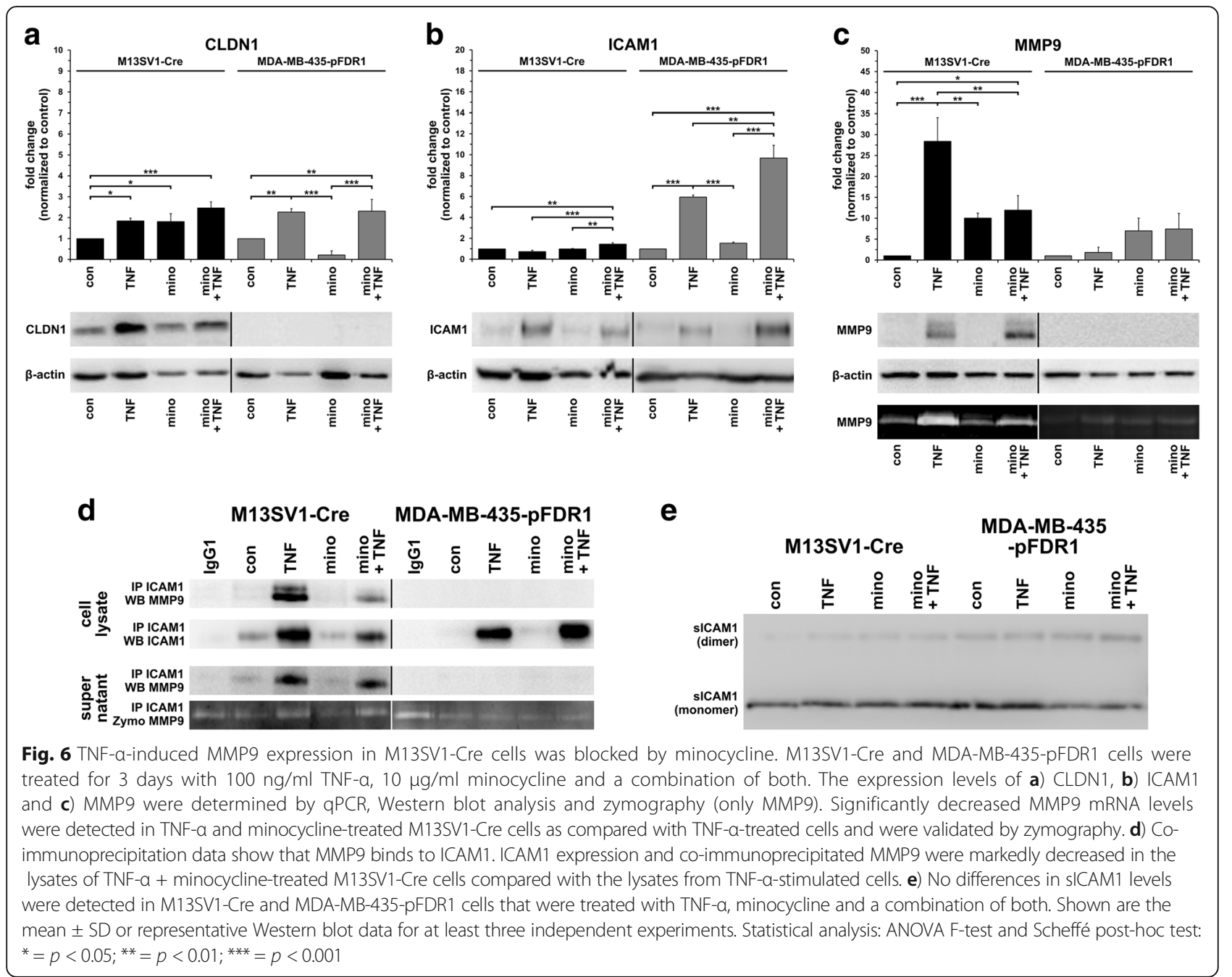

markers in breast cancer, melanoma and glioblastoma cell lines might be related to lineage infidelity, which seems to be a common phenomenon in cancer cells lines [37]. In agreement with MCF-7 breast cancer cells, but in contrast to melanoma cells, the expression of breast epitheliumspecific and epithelial-specific markers, such as $\beta$-casein, $\alpha$-lactalbumin, epithelial membrane antigen (EMA), and keratin-19 as well as the induction of $\beta$-casein expression and production of milk lipids by $\beta$-heregulin and vitamin $\mathrm{E}$ was clearly observed in MDA-MB-435 cells [38]. Moreover, MDA-MB-435 xenograft studies revealed that the vast majority of the cells were positive for cytokeratin and EMA, suggesting that MDA-MB-435 is a breast epithelial cell line that has gained melanocyte lineage characteristics [38].

Our data indicate that the TNF- $\alpha$-induced fusion of M13SV1-Cre and MDA-MB-435-pFDR1 cells depends on MMP9. Blocking MMP9 with a specific inhibitor or the inhibition of MMP9 expression using minocycline was associated with a decreased cell fusion frequency.
These data agree with that of several studies that have already demonstrated that TNF- $\alpha$ and/or MMP9 play a role in the fusion of different cell types [16-19, 39-41]. For instance, Song et al. showed that TNF- $\alpha$ enhanced the fusion of oral squamous carcinoma cells and endothelial cells via a VCAM-1/VLA-4-dependent pathway [19]. MMP9 was not investigated in this particular study and it is unclear whether it is involved in the fusion of these cells. TNF- $\alpha$-induced VCAM-1 expression in endothelial cells is crucial for close cell-cell contact and is a prerequisite for the subsequent plasma membrane fusion step. Here, TNF- $\alpha$ induced ICAM1 expression in both cell types, but no reduced cell fusion rate was observed in the presence of an ICAM1 blocking antibody. It is likely indicating that the TNF- $\alpha$-induced fusion of M13SV1-Cre and MDA-MB-435-pFDR1 was independent of ICAM1. Nonetheless, ICAM1 was recently identified to augment myoblast adhesion and fusion through homophilic trans-interactions and Racmediated actin remodelling [28]. Therefore, the 


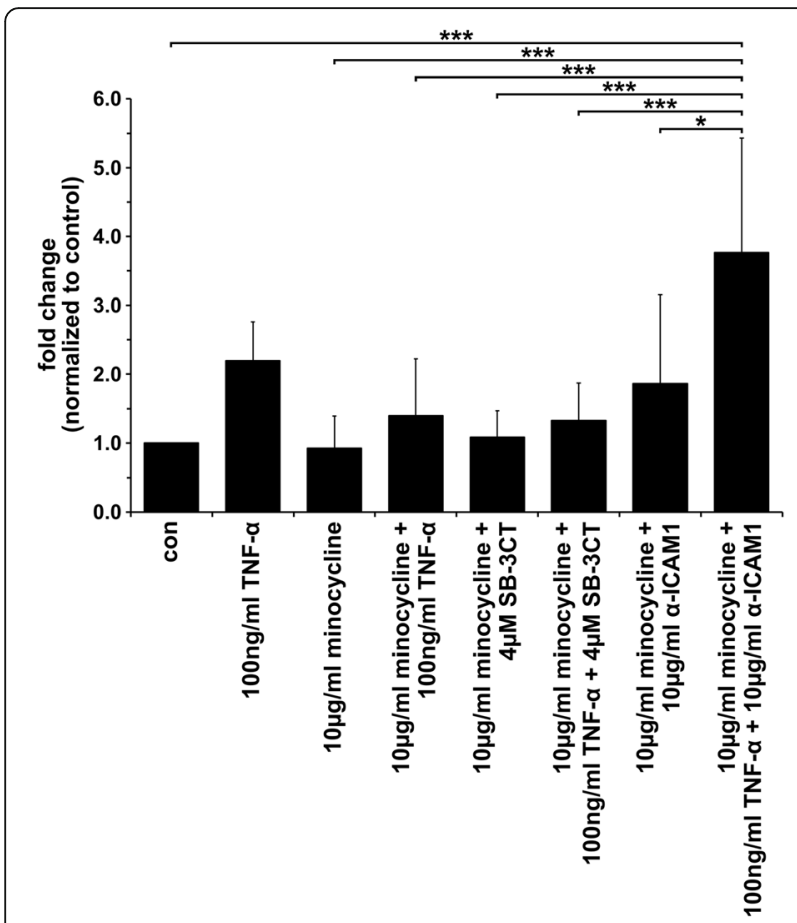

Fig. 7 The co-administration of minocycline, SB-3CT and the ICAM1 blocking antibody, yielded different results. No additive inhibitory effect of minocycline and SB-3CT regarding the TNF-a-induced fusion of M13SV1-Cre and MDA-MB-435-pFDR1 cells was observed. In contrast, the incubation of cells in the presence of minocycline, ICAM1 blocking antibody and TNF-a yielded a significantly increased fusion rate. The data shown are the mean \pm SD of at least three independent experiments. Statistical analysis: ANOVA F-test and Scheffé posthoc test: ${ }^{*}=p<0.05 ;{ }^{* *}=p<0.01 ;{ }^{* *}=p<0.001$

fusogenic property of ICAM1-ICAM1 interactions was restricted to myogenic cells, as forced expression of ICAM1 by fibroblasts did not augment their fusion to ICAM1-positive myoblasts/myotubes [28].

MMP9 is involved in macrophage fusion. The IL-4 induced fusion of macrophages was reduced in the presence of MMP9 function-blocking antibodies and similar effects were also observed in MMP9 null-macrophages, clearly showing the impact of MMP9 in macrophage fusion [40]. Likewise, MMP9, E-cadherin and DCSTAMP were upregulated by both IL-4 signalling and DAP12 signalling in macrophages and DAP12 overexpression induced macrophage fusion [39]. Conversely, DAP12 deficiency was associated with an impaired frequency of macrophage fusion because of low MMP9 levels [39]. Low MMP9 expression levels, concomitant with a decreased macrophage fusion rate, were also found in MCP-1/CCL2-null mice [16]. Moreover, the impaired fusion capacity of MCP-1/CCL2-null macrophages is rescued by exogenous TNF- $\alpha$ and TNF- $\alpha-$ induced MMP9 expression [16], which agrees with our data. The finding that TNF- $\alpha$ could induce fusion via an MMP9-dependent mechanism is further supported by data showing that the fusion of osteoclasts in bone explants, which were stimulated by human breast cancer cells through TNF- $\alpha$ secretion, could be blocked by the inhibition of MMP9 [41].

Even though these findings indicate a correlation between the induction of MMP9 expression and cell fusion, the detailed mechanism of how MMP9 is involved in the merging of plasma membranes still remains unclear. Cell fusion is a multi-step process that can be subdivided into i) priming, ii) chemotaxis, iii) adhesion, iv) fusion, and v) post-fusion. IL-4 and DAP12 signalling program cells into a fusion-competent status [4, 39], whereas MCP-1/CCL2 signalling is associated with chemotaxis $[4,16]$. Because TNF- $\alpha$ induces cell fusion, it might be capable of programming cells into a fusioncompetent status. Because of its proteolytic activity, MMP9 may degrade extra-cellular matrix components, promote interaction with cell membranes or may induce signal molecules necessary for cell fusion [4, 40]. We wondered whether MMP9 may degrade membranebound ICAM1, which may allow the plasma membranes of two cells to come into close contact. Tsai and colleagues recently demonstrated that TNF- $\alpha$ induced an MMP9-dependent release of soluble ICAM1 release in osteoblast-like MC3T3-E1 cells [31]. However, increased levels of soluble ICAM1 were not observed in TNF- $\alpha$ treated cells nor was the TNF- $\alpha$ induced fusion of the cells inhibited by an ICAM1 blocking antibody.

Whether CCL2 might be involved in the TNF- $\alpha-$ induced fusion of M13SV1-Cre and MDA-MB-435pFDR1 cells remains unclear. Markedly increased CCL2 expression levels were only observed in TNF- $\alpha$ stimulated MDA-MB-435-pFDR1 cells. CCL2 might conceivably be involved in the induction of chemotaxis in M13SV1-Cre cells.

The finding that MMP9 plays a role in the TNF- $\alpha$ induced fusion of M13SV1-Cre and MDA-MB-435pFDR1 cells was further supported by minocycline studies, which revealed markedly lower MMP9 expression levels and a reduced fusion rate in the presence of TNF$\alpha$. This finding agrees with in vitro and in vivo studies that show that both tumour growth and osseous metastasis of breast cancer cells was effectively reduced by minocycline because of its inhibition of MMP9 expression [42-44]. It is well-known that besides its bacteriostatic efficacy against both gram-positive and gram-negative bacteria, minocycline also possesses anti-inflammatory properties (for review see: [25]). The mechanisms involved in the anti-inflammatory activity of minocycline include its inhibitory effects on the activity of enzymes such as iNOS, the MMPs or COX2, the inhibition of apoptosis and the inhibition of immune cell activation and proliferation [25]. Several lines of evidence indicated that minocycline exerted its inhibitory 
effects mainly through the inhibition of the NF- $\mathrm{BB}$ pathway [45-48]. Minocycline attenuates bone cancer pain in rats by significantly decreasing both the total and nuclear expression of NF- $\mathrm{KB}$ and $\mathrm{p}-\mathrm{IKK} \alpha$ in astrocytes [46]. Consistent with these findings, minocycline significantly suppresses $I K K \alpha / \beta$ phosphorylation in LPS-stimulated THP-1 monocytic cells, suggesting that it inhibits NF- $\mathrm{KB}$ signalling at the level of IKK $\alpha / \beta$ phosphorylation [48]. This agrees with the data that show that minocycline suppresses constitutive NF- $\mathrm{kB}$ activation in OVCAR-3 and SKOV-3 ovarian carcinoma cells, which is correlated with the attenuation of IKK activation [47]. Interestingly, further data revealed that the minocyclineinduced suppression of NF- $\mathrm{KB}$ activity was mediated, in part, through the inhibition of TGF- $\beta 1$ [47]. It is wellknown that TNF- $\alpha$ signals via NF- $\mathrm{kB}$ [49]. Hence, minocycline most likely impairs TNF- $\alpha$-induced cell fusion by blocking MMP9 expression in M13SV1-Cre cells because of the inhibition of NF- $\mathrm{kB}$ signalling.

\section{Conclusions}

Our data indicate that the matrix metalloproteinase MMP9 is involved in the TNF- $\alpha$-induced fusion of M13SV1-Cre cells and MDA-MB-435-pFDR1 cells. Likewise, the tetracycline-based antibiotic minocycline effectively impaired the TNF- $\alpha$-induced fusion of the cells because of the inhibition of MMP9 expression.

\section{Additional files}

Additional file 1: Differentially-regulated genes in TNF-a-treated M13SV1-Cre and MDA-MB-435-pFDR1 cells under normoxic and hypoxic conditions. Genes that were up-regulated and down-regulated by at least 2-fold in TNF-a-treated cells compared with untreated cells (not detected flags and compromised spots were not removed). Genes shown in Fig. 1 are marked in yellow. (XLSX $29 \mathrm{~kb}$ )

Additional file 2: Proliferation of M13SV1-Cre and MDA-MB-435-oFDR1 cells was impaired in a dose-dependent manner by minocycline. Cells were cultivated for up to $72 \mathrm{~h}$ with different minocycline concentrations. The data shown are the mean \pm SD of three independent experiments. (TIFF $478 \mathrm{~kb}$ )

\footnotetext{
Abbreviations

ABCC6: ATP binding cassette subfamily C member 6; ADAMTS9: A disintegrin and metalloproteinase with thrombospondin motifs 9; BMDCs: Bone marrow-derived stem cells; CCL2: CC-chemokine ligand 2; CLDN1: Claudin-1; COL27A1: Collagen type XXVII alpha 1 chain; DC-STAMP: Dendritic cell-specific transmembrane antigen; DMEM: Dulbecco's Minimal Essential Medium; EGF: Epidermal growth factor; EMA: Epithelial membrane antigen; ESA: Epithelial specific antigen; FCS: Foetal calf serum; FDR: Fluorescence double reporter; ICAM1: Intercellular cell adhesion molecule 1; ICAM2: Intercellular cell adhesion molecule 2; ICAM4: Intercellular cell adhesion molecule 4; IL-13: Interleukin-13; IL32: Interleukin 32; IL-4: Interleukin-4; IL411: Interleukin 4 induced 1; IL7R: Interleukin 7 receptor; LAMB3: Laminin subunit beta 3; LAMC2: Laminin subunit gamma 2; IncRNA: Long non-coding RNA; MCSF: Macrophage-colony stimulating factor; miRNA: microRNA; MMP9: Matrix metalloproteinase 9; MUC4: Mucin 4; NF-kB: Nuclear factor-kappa B; OCSTAMP: Osteoclast stimulatory transmembrane antigen; PBS: Phosphate-buffered saline; PCR: Polymerase chain reaction; qPCR: Quantitative polymerase chain reaction; RANKL: Receptor activator of nuclear factor kappa-B ligand; RIN: RNA integrity number; SDS-PAGE: Sodium dodecyl sulphate-polyacrylamide gel
}

electrophoresis; sICAM1: Soluble intercellular cell adhesion molecule 1; SIRPa: Signal-regulatory protein alpha; TNF-a: Tumour necrosis factor-a; TNFAIP3: Tumour necrosis factor-alpha induced protein 3; VEGFC: Vascular endothelial growth factor C; ZBAF: Centre for Biomedical Education and Research

\section{Acknowledgements}

The authors are grateful to Frank Edenhofer from the Institute of Anatomy and Cell Biology, Julian-Maximilians-University of Würzburg, Würzburg, Germany for providing us with the pFDR1 vector. Likewise, the authors would like to thank Jan Postberg and Patrick Weil from the HELIOS Medical Centre Wuppertal, Wuppertal, Germany for helping us with the Agilent 2100 Bioanalyzer. Furthermore, we are grateful to Thomas Ostermann and Sebastian Appelbaum from the Department of Psychology and Psychotherapy, Witten/Herdecke University, for helping us with the statistical analysis.

\section{Funding}

This work was supported by the Fritz-Bender Foundation, Munich, Germany.

\section{Availability of data and materials}

The datasets used and/or analysed during the current study are available from the corresponding author upon reasonable request.

\section{Authors' contributions}

JW performed the experiments, analysed the data, wrote and corrected the manuscript. MM prepared samples for CDNA microarray data analysis; analysed and validated the CDNA microarray data. KSZ read and corrected the manuscript. TD designed the experiments and wrote and corrected the manuscript. All authors read and approved the final manuscript.

Ethics approval and consent to participate

Not applicable.

\section{Consent for publication}

Not applicable.

\section{Competing interests}

The authors declare that they have no competing interests.

\section{Publisher's Note}

Springer Nature remains neutral with regard to jurisdictional claims in published maps and institutional affiliations.

\section{Author details}

${ }^{1}$ Institute of Immunology, Centre of Biomedical Education and Research (ZBAF), Witten/Herdecke University, Stockumer Str. 10, 58448 Witten, Germany. ${ }^{2}$ BioGenes GmbH, Köpenicker Str. 325, 12555 Berlin, Germany.

Received: 1 March 2018 Accepted: 2 April 2018

Published online: 10 April 2018

\section{References}

1. Aguilar PS, Baylies MK, Fleissner A, Helming L, Inoue N, Podbilewicz B, Wang $\mathrm{H}$, Wong M. Genetic basis of cell-cell fusion mechanisms. Trends Genet. 2013;29(7):427-37. https://doi.org/10.1016/j.tig.2013.01.011.

2. Dittmar T, Zanker KS. Cell fusion in health and disease. Volume II, vol 2. Adv Exp med biol. Dordrecht, The Netherlands: Springer; 2011.

3. Dittmar T, Zänker KS. Cell fusion in health and disease: volume I, vol 1. Adv Exp med biol. Dordrecht, The Netherlands: Springer; 2011.

4. Zhou X, Platt JL. Molecular and cellular mechanisms of mammalian cell fusion. Adv Exp Med Biol. 2011;713:33-64. https://doi.org/10.1007/978-94007-0763-4_4.

5. Huppertz B, Bartz C, Kokozidou M. Trophoblast fusion: fusogenic proteins, syncytins and ADAMs, and other prerequisites for syncytial fusion. Micron. 2006;37(6):509-17.

6. Bastida-Ruiz D, Van Hoesen K, Cohen M. The dark side of cell fusion. Int J Mol Sci. 2016;17(5) https://doi.org/10.3390/ijms17050638.

7. Omata W, WEt A, Vandre DD, Robinson JM. Trophoblast cell fusion and differentiation are mediated by both the protein kinase $C$ and a pathways. PLoS One. 2013;8(11):e81003. https://doi.org/10.1371/journal.pone.0081003.

8. Abmayr SM, Pavlath GK. Myoblast fusion: lessons from flies and mice. Development. 2012;139(4):641-56. https://doi.org/10.1242/dev.068353. 
9. Helming L, Gordon S. Molecular mediators of macrophage fusion. Trends Cell Biol. 2009;19:514-22. https://doi.org/10.1016/j.tcb.2009.07.005.

10. Melzer C, von der Ohe J, Hass R. Enhanced metastatic capacity of breast cancer cells after interaction and hybrid formation with mesenchymal stroma/stem cells (MSC). Cell Commun Signal. 2018;16(1):2. https://doi.org/ 10.1186/s12964-018-0215-4

11. Vignery A. Macrophage fusion: the making of osteoclasts and giant cells. J Exp Med. 2005;202(3):337-40.

12. Alvarez-Dolado M, Pardal R, Garcia-Verdugo JM, Fike JR, Lee HO, Pfeffer K, Lois C, Morrison SJ, Alvarez-Buylla A. Fusion of bone-marrow-derived cells with Purkinje neurons, cardiomyocytes and hepatocytes. Nature. 2003; 425(6961):968-73.

13. Davies PS, Powell AE, Swain JR, Wong MH. Inflammation and proliferation act together to mediate intestinal cell fusion. PLoS One. 2009;4(8):e6530. https://doi.org/10.1371/journal.pone.0006530.

14. Skinner AM, Grompe M, Kurre P. Intra-hematopoietic cell fusion as a source of somatic variation in the hematopoietic system. J Cell Sci. 2012;125(Pt 12): 2837-43. https://doi.org/10.1242/jcs.100123.

15. Johansson CB, Youssef S, Koleckar K, Holbrook C, Doyonnas R, Corbel SY, Steinman L, Rossi FM, Blau HM. Extensive fusion of haematopoietic cells with Purkinje neurons in response to chronic inflammation. Nat Cell Biol. 2008;10(5):575-83.

16. Skokos EA, Charokopos A, Khan K, Wanjala J, Kyriakides TR. Lack of TNFalpha-induced MMP-9 production and abnormal E-cadherin redistribution associated with compromised fusion in MCP-1-null macrophages. Am J Pathol. 2011;178:2311-21. https://doi.org/10.1016/j. ajpath.2011.01.045.

17. Hotokezaka H, Sakai E, Ohara N, Hotokezaka Y, Gonzales C, Matsuo K, Fujimura Y, Yoshida N, Nakayama K. Molecular analysis of RANKLindependent cell fusion of osteoclast-like cells induced by TNF-alpha, lipopolysaccharide, or peptidoglycan. J Cell Biochem. 2007;101(1):122-34. https://doi.org/10.1002/jcb.21167.

18. Mohr M, Tosun S, Arnold WH, Edenhofer F, Zanker KS, Dittmar T. Quantification of cell fusion events human breast cancer cells and breast epithelial cells using a Cre-LoxP-based double fluorescence reporter system. Cell Mol Life Sci. 2015;72(19):3769-82. https://doi.org/ 10.1007/s00018-015-1910-6.

19. Song K, Zhu F, Zhang HZ, Shang ZJ. Tumor necrosis factor-alpha enhanced fusions between oral squamous cell carcinoma cells and endothelial cells via VCAM-1NLA-4 pathway. Exp Cell Res. 2012;318(14):1707-15. https://doi. org/10.1016/j.yexcr.2012.05.022

20. Balkwill F, Mantovani A. Inflammation and cancer: back to Virchow? Lancet. 2001;357(9255):539-45. https://doi.org/10.1016/S0140-6736(00)04046-0.

21. Dvorak HF. Tumors: wounds that do not heal. Similarities between tumor stroma generation and wound healing. N Engl J Med. 1986; 315(26):1650-9.

22. Dittmar T, Zanker KS. Tissue regeneration in the chronically inflamed tumor environment: implications for cell fusion driven tumor progression and therapy resistant tumor hybrid cells. Int J Mol Sci. 2015;16(12):30362-81. https://doi.org/10.3390/ijms161226240.

23. Duelli D, Lazebnik Y. Cell fusion: a hidden enemy? Cancer Cell. 2003;3(5):445-8.

24. Lu X, Kang Y. Cell fusion as a hidden force in tumor progression. Cancer Res. 2009;69(22):8536-9.

25. Garrido-Mesa N, Zarzuelo A, Galvez J. Minocycline: far beyond an antibiotic. Br J Pharmacol. 2013;169(2):337-52. https://doi.org/10.1111/ bph.12139.

26. Nolden L, Edenhofer F, Haupt S, Koch P, Wunderlich FT, Siemen H, Brustle $O$. Site-specific recombination in human embryonic stem cells induced by cell-permeant Cre recombinase. Nat Methods. 2006;3(6):461-7. https://doi. org/10.1038/nmeth884

27. Chang CC, Sun W, Cruz A, Saitoh M, Tai MH, Trosko JE. A human breast epithelial cell type with stem cell characteristics as target cells for carcinogenesis. Radiat Res. 2001;155(1 Pt 2):201-7.

28. Pizza FX, Martin RA, Springer EM, Leffler MS, Woelmer BR, Recker IJ, Leaman DW. Intercellular adhesion molecule-1 augments myoblast adhesion and fusion through homophilic trans-interactions. Sci Rep. 2017;7(1):5094. https://doi.org/10.1038/s41598-017-05283-3.

29. Hu C, Li H, Li J, Zhu Z, Yin S, Hao X, Yao M, Zheng S, Gu J. Analysis of $A B C G 2$ expression and side population identifies intrinsic drug efflux in the HCC cell line MHCC-97L and its modulation by Akt signaling. Carcinogenesis. 2008;29(12):2289-97.
30. Brundula V, Rewcastle NB, Metz LM, Bernard CC, Yong WW. Targeting leukocyte MMPs and transmigration: minocycline as a potential therapy for multiple sclerosis. Brain. 2002;125(Pt 6):1297-308.

31. Tsai CL, Chen WC, Hsieh HL, Chi PL, Hsiao LD, Yang CM. TNF-alpha induces matrix metalloproteinase-9-dependent soluble intercellular adhesion molecule-1 release via TRAF2-mediated MAPKs and NF-kappaB activation in osteoblast-like MC3T3-E1 cells. J Biomed Sci. 2014;21:12. https://doi.org/10. 1186/1423-0127-21-12.

32. Ross DT, Scherf $U$, Eisen MB, Perou CM, Rees C, Spellman P, lyer V, Jeffrey SS, Van de Rijn M, Waltham M, Pergamenschikov A, Lee JC, Lashkari D, Shalon $D$, Myers TG, Weinstein JN, Botstein D, Brown PO. Systematic variation in gene expression patterns in human cancer cell lines. Nat Genet. 2000;24(3): 227-35. https://doi.org/10.1038/73432.

33. Rae JM, Creighton CJ, Meck JM, Haddad BR, Johnson MD. MDA-MB-435 cells are derived from M14 melanoma cells-a loss for breast cancer, but a boon for melanoma research. Breast Cancer Res Treat. 2006;104(1):13-9.

34. Paz MF, Fraga MF, Avila S, Guo M, Pollan M, Herman JG, Esteller M. A systematic profile of DNA methylation in human cancer cell lines. Cancer Res. 2003;63(5):1114-21.

35. Prat A, Parker JS, Karginova O, Fan C, Livasy C, Herschkowitz Jl, He X, Perou CM. Phenotypic and molecular characterization of the claudin-low intrinsic subtype of breast cancer. Breast Cancer Res. 2010;12(5):R68. https://doi.org/ $10.1186 / \mathrm{bcr} 2635$

36. Garraway LA, Widlund HR, Rubin MA, Getz G, Berger AJ, Ramaswamy S, Beroukhim R, Milner DA, Granter SR, Du J, Lee C, Wagner SN, Li C, Golub TR, Rimm DL, Meyerson ML, Fisher DE, Sellers WR. Integrative genomic analyses identify MITF as a lineage survival oncogene amplified in malignant melanoma. Nature. 2005;436(7047):117-22. https://doi.org/10.1038/ nature03664.

37. Zhang Q, Fan H, Shen J, Hoffman RM, Xing HR. Human breast cancer cell lines co-express neuronal, epithelial, and melanocytic differentiation markers in vitro and in vivo. PLoS One. 2010;5(3):e9712. https://doi.org/10.1371/ journal.pone.0009712.

38. Sellappan S, Grijalva R, Zhou X, Yang W, Eli MB, Mills GB, Yu D. Lineage infidelity of MDA-MB-435 cells: expression of melanocyte proteins in a breast cancer cell line. Cancer Res. 2004;64(10):3479-85.

39. Helming L, Tomasello E, Kyriakides TR, Martinez FO, Takai T, Gordon S, Vivier E. Essential role of DAP12 signaling in macrophage programming into a fusion-competent state. Sci Signal. 2008;1:ra11. https://doi.org/10.1126/ scisignal.1159665.

40. MacLauchlan S, Skokos EA, Meznarich N, Zhu DH, Raoof S, Shipley JM, Senior RM, Bornstein P, Kyriakides TR. Macrophage fusion, giant cell formation, and the foreign body response require matrix metalloproteinase 9. J Leukoc Biol. 2009;85(4):617-26. https://doi.org/10.1189/jlb.1008588.

41. Tumber A, Morgan HM, Meikle MC, Hill PA. Human breast-cancer cells stimulate the fusion, migration and resorptive activity of osteoclasts in bone explants. Int J Cancer. 2001;91(5):665-72.

42. Hu F, Ku MC, Markovic D, a Dzaye OD, Lehnardt S, Synowitz M, Wolf SA, Kettenmann $\mathrm{H}$. Glioma-associated microglial MMP9 expression is upregulated by TLR2 signaling and sensitive to minocycline. Int J Cancer. 2014:135(11):2569-78. https://doi.org/10.1002/ijc.28908.

43. Markovic DS, Vinnakota K, van Rooijen N, Kiwit J, Synowitz M, Glass R, Kettenmann $\mathrm{H}$. Minocycline reduces glioma expansion and invasion by attenuating microglial MT1-MMP expression. Brain Behav Immun. 2011;25(4): 624-8. https://doi.org/10.1016/j.bbi.2011.01.015.

44. Niu G, Liao Z, Cai L, Wei R, Sun L. The combined effects of celecoxib and minocycline hydrochloride on inhibiting the osseous metastasis of breast cancer in nude mice. Cancer Biother Radiopharm. 2008;23(4):469-76. https:// doi.org/10.1089/cbr.2008.0475.

45. Cai Z, Zhao Y, Yao S, Bin Zhao B. Increases in beta-amyloid protein in the hippocampus caused by diabetic metabolic disorder are blocked by minocycline through inhibition of NF-kappaB pathway activation. Pharmacol Rep. 2011;63(2):381-91.

46. Song ZP, Xiong BR, Guan XH, Cao F, Manyande A, Zhou YQ, Zheng H, Tian YK. Minocycline attenuates bone cancer pain in rats by inhibiting NFkappaB in spinal astrocytes. Acta Pharmacol Sin. 2016;37(6):753-62. https:// doi.org/10.1038/aps.2016.1.

47. Ataie-Kachoie P, Badar S, Morris DL, Pourgholami MH. Minocycline targets the NF-kappaB Nexus through suppression of TGF-beta1-TAK1-IkappaB signaling in ovarian cancer. Mol Cancer Res. 2013;11(10):1279-91. https:// doi.org/10.1158/1541-7786.MCR-13-0239. 
48. Tai K, Iwasaki H, Ikegaya S, Ueda T. Minocycline modulates cytokine and chemokine production in lipopolysaccharide-stimulated THP-1 monocytic cells by inhibiting IkappaB kinase alpha/beta phosphorylation. Transl Res. 2013;161(2):99-109. https://doi.org/10.1016/j.trsl.2012.10.001

49. Kalliolias GD, Ivashkiv LB. TNF biology, pathogenic mechanisms and emerging therapeutic strategies. Nat Rev Rheumatol. 2016;12(1):49-62. https://doi.org/10.1038/nrrheum.2015.169.

- fast, convenient online submission

- thorough peer review by experienced researchers in your field

- rapid publication on acceptance

- support for research data, including large and complex data types

- gold Open Access which fosters wider collaboration and increased citations

- maximum visibility for your research: over $100 \mathrm{M}$ website views per year 